\title{
A molecular-level perspective on the frequency, distribution, and consequences of messenger RNA modifications
}

\author{
Joshua D. Jones $^{1} \quad$ | Jeremy Monroe ${ }^{1} \quad$ Kristin S. Koutmou ${ }^{1,2}$ (1)
}

${ }^{1}$ Department of Chemistry, University of Michigan, Ann Arbor, Michigan

${ }^{2}$ Program in Chemical Biology, University of Michigan, Ann Arbor, Michigan

Correspondence

Kristin S. Koutmou, Department of Chemistry, University of Michigan, $930 \mathrm{~N}$ University, Ann Arbor, MI 48109.

Email: kkoutmou@umich.edu

Funding information National Institutes of Health, Grant/ Award Number: R35 GM128836; University of Michigan

\begin{abstract}
Cells use chemical modifications to alter the sterics, charge, and conformations of large biomolecules, modulating their biogenesis, function, and stability. Until recently post-transcriptional RNA modifications were thought to be largely limited to nonprotein coding RNA species. However, this dogma has rapidly transformed with the discovery of a host of modifications in protein coding messenger RNAs (mRNAs). Recent advancements in genome-wide sequencing technologies have enabled the identification of mRNA modifications as a potential new frontier in gene regulation-leading to the development of the epitranscriptome field. As a result, there has been a flurry of multiple groundbreaking discoveries, including new modifications, nucleoside modifying enzymes ("writers" and "erasers"), and RNA binding proteins that recognize chemical modifications ("readers"). These discoveries opened the door to understanding how post-transcriptional mRNA modifications can modulate the mRNA lifecycle, and established a link between the epitranscriptome and human health and disease. Despite a rapidly growing recognition of their importance, fundamental questions regarding the identity, prevalence, and functional consequences of mRNA modifications remain to be answered. Here, we highlight quantitative studies that characterize mRNA modification abundance, frequency, and interactions with cellular machinery. As the field progresses, we see a need for the further integration of quantitative and reductionist approaches to complement transcriptome wide studies in order to establish a molecular-level framework for understanding the consequences of mRNA chemical modifications on biological processes.
\end{abstract}

This article is categorized under:

RNA Structure and Dynamics $>$ RNA Structure, Dynamics and Chemistry

RNA Processing $>$ RNA Editing and Modification

\section{K E Y W O R D S}

epitranscriptome, mRNA modification 


\section{INTRODUCTION}

Chemical modifications have been studied as key modulators of RNA biogenesis, function, and stability for over half a century (Cohn \& Volkin, 1951; F. F. Davis \& Worthington Allen, 1957; Helm \& Alfonzo, 2017; R. P. Perry, Kelley, Friderici, \& Rottman, 1975; Rottman, Shatkin, \& Perry, 1974). Until recently, post-transcriptional modifications were thought to be largely limited to noncoding RNAs (ncRNAs), as only three modifications, N7-methylguanosine $\left(\mathrm{m}^{7} \mathrm{G}\right)$, N6-methyladenosine $\left(\mathrm{m}^{6} \mathrm{~A}\right)$, and inosine (I), were known in protein coding messenger RNAs (mRNAs) (Desrosiers, Friderici, \& Rottman, 1974; Morse \& Bass, 1997; Nachtergaele \& He, 2017; Paul, 1998; R. P. Perry \& Kelley, 1974). The discovery of over a dozen enzymatically incorporated modifications in mRNAs has shifted this paradigm and generated tremendous interest because mRNA modifications have the potential to control protein expression (Figure 1; Frye, Harada, Behm, \& He, 2018; Gilbert, Bell, \& Schaening, 2016).

It is still unclear if most modifications result from background off-target activities of ncRNA modifying enzymes, or if they represent a new layer of post-transcriptional control. Regardless, there are likely to be biological consequences for mRNA modifications, as these chemical tags can influence the interactions between mRNAs and the cellular machinery. The study of mRNA modifications (the epitranscriptome, Figure 2) is a rapidly emerging field as researchers seek to establish the influence of mRNA modifications on biology and human health (Gilbert et al., 2016; Hoernes, Huttenhofer, \& Erlacher, 2016; Nachtergaele \& He, 2017; Peer, Rechavi, \& Dominissini, 2017; Roundtree, Evans, Pan, \& He, 2017; Saletore et al., 2012). Initial correlative studies have revealed links between a subset of modifications and essential biological functions including development, sex determination and circadian rhythm maintenance, multiple cancers, and diseases (Angelova et al., 2018; Q. Cui et al., 2017; De Jesus et al., 2019; Fustin et al., 2018; Haussmann et al., 2016; L. J. Li, Fan, Leng, Pan, \& Ye, 2018; Lin, Choe, Du, Triboulet, \& Gregory, 2016; Roundtree, Evans, et al., 2017; Sibbritt, Patel, \& Preiss, 2013; Yoon et al., 2017; Zhang et al., 2016; Zhong et al., 2018). However, key fundamental questions regarding the incorporation and molecular-level consequences of mRNA modification need to be investigated to understand how mRNA modification status contributes to discrete biological processes and disease states (Figure 3).

The mRNA epitranscriptome is chemically diverse, containing nucleoside isomers, methyl, acetyl, hydroxymethyl, and formyl modifications (Figure 2; Arango et al., 2018; Carlile et al., 2014; Delatte et al., 2016; Dominissini et al., 2016; Huber et al., 2015; Jia et al., 2011; Lovejoy, Riordan, \& Brown, 2014; S. Schwartz et al., 2014; Squires et al., 2012; Tardu, Jones, Kennedy, Lin, \& Koutmou, 2019; Xu et al., 2017). Modifications are present in eukaryotic, bacterial, and viral mRNAs (Deng et al., 2015; Kennedy, Courtney, Tsai, \& Cullen, 2017). Advances in sequencing technologies enabled the development of techniques to identify the location of modifications transcriptome wide (Amort et al., 2017; Delatte

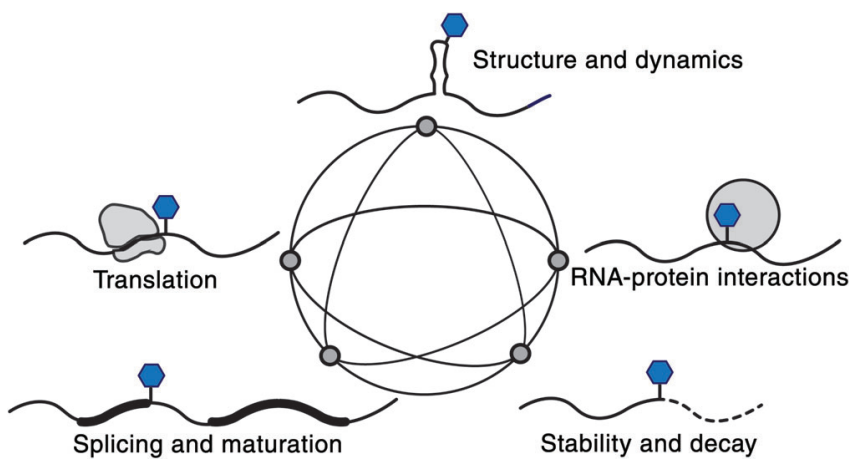

F I G U R E 1 Chemical modifications have the potential to individually influence mRNA structure and dynamics, splicing and maturation, RNA-protein interactions, translation, and stability. The interconnected nature of the mRNA life cycle can intensify the effect of a modification through the modulation of downstream processes. For example, several mRNA modifications, $\mathrm{m}^{6} \mathrm{~A}, \mathrm{~m}^{1} \mathrm{~A}, \mathrm{~m}^{1} \mathrm{G}, \Psi$, and $\mathrm{f}^{5} \mathrm{C}$, have been shown to change the stability of RNA structures and would be predicted to redistribute the ensemble of mRNA secondary structures present in a cell (Charette \& Gray, 2000; D. R. Davis, 1995; B. Liu et al., 2018; Roost et al., 2015; Spitale et al., 2015; R. Wang et al., 2016; Zhou et al., 2016). This alteration can modulate the ability to form RNA-protein interactions, which can in turn impact mRNA maturation, translation, and decay through pathways dependent on these interactions. Additionally, mRNA translation rates and mRNA decay rates are coupled, with poorly translated mRNAs being targeted more robustly for decay (Presnyak et al., 2015; Radhakrishnan et al., 2016). Thus, if an mRNA modification strongly impacts one step in an mRNA's life, this perturbation is likely to be observed in the outcome of related processes (e.g., modification induced perturbations in mRNA structure could slow translation, which in turn reduces the mRNA's half-life) 

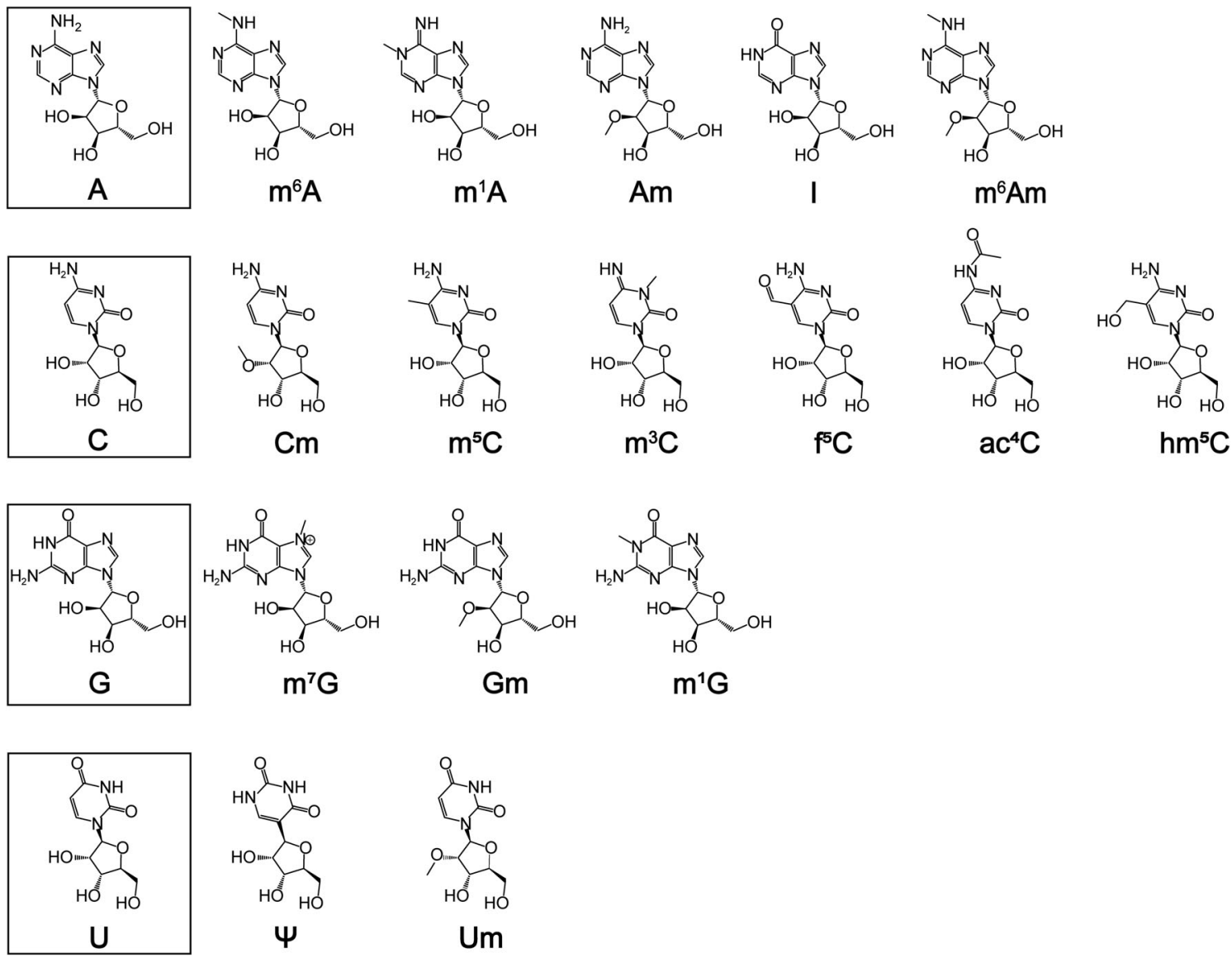

F I G U RE 2 Reported messenger RNA (mRNA) modifications. Unmodified nucleosides are shown in boxes, while the modified nucleosides are unboxed. The full names of the nucleosides are: $\mathrm{A}$, adenosine; $\mathrm{m}^{6} \mathrm{~A}, \mathrm{~N}^{6}$-methyladenosine; $\mathrm{m}^{1} \mathrm{~A}, 1$-methyladenosine; Am, $2^{\prime}$ O-methyladenosine; I, inosine; $\mathrm{m}^{6} \mathrm{Am}, \mathrm{N}^{6}, 2^{\prime}$-O-dimethyladenosine; $\mathrm{C}$, cytidine; $\mathrm{Cm}, 2^{\prime}$-O-methylcytidine; $\mathrm{m}^{5} \mathrm{C}, 5$-methylcytidine; $\mathrm{m}^{3} \mathrm{C}$, 3-methylcytidine; $\mathrm{f}^{5} \mathrm{C}$, 5-formylcytidine; $\mathrm{ac}^{4} \mathrm{C}, \mathrm{N}^{4}$-acetylytidine; $\mathrm{hm}^{5} \mathrm{C}$, 5-hydroxymethylcytidine; $\mathrm{G}$, guanosine; $\mathrm{m}^{7} \mathrm{G}, 7$-methylguanosine; $\mathrm{Gm}, 2^{\prime}$-O-methylguanosine; $\mathrm{m}^{1} \mathrm{G}$, 1-methylguanosine; $\mathrm{U}$, uridine; $\Psi$, pseudouridine; $\mathrm{Um}, 2^{\prime}$-O-methyluridine

et al., 2016; Motorin \& Helm, 2019). These approaches have given us an expansive bird's-eye view of mRNA modifications by providing detailed maps of where 12 modifications can be incorporated into the transcriptome [N6-methyladenosine $\left(\mathrm{m}^{6} \mathrm{~A}\right)$ pseudouridine $(\Psi)$, N4-acetylcytidine $\left(\operatorname{ac}^{4} \mathrm{C}\right), \quad$ N1-methyladenosine $\quad\left(\mathrm{m}^{1} \mathrm{~A}\right)$, N7-methylguanosine $\left(\mathrm{m}^{7} \mathrm{G}\right)$, 2'O-methyl modifications $(\mathrm{Cm}, \mathrm{Am}, \mathrm{Gm}, \mathrm{Um})$, 5-methylcytidine $\left(\mathrm{m}^{5} \mathrm{C}\right)$, and 5-hydroxymethylcytidine $\left(\mathrm{hm}^{5} \mathrm{C}\right)$, and inosine (I)] (Alon et al., 2015; Amort et al., 2017; Arango et al., 2018; Carlile et al., 2014; X. Cui et al., 2017; Danecek et al., 2012; Delatte et al., 2016; Dominissini et al., 2012; Garcia-Campos et al., 2019; Kim et al., 2004; Levanon et al., 2004; X. Li et al., 2015; Lovejoy et al., 2014; Meyer et al., 2012; Sakurai, Yano, Kawabata, Ueda, \& Suzuki, 2010; S. Schwartz et al., 2014; Squires et al., 2012; Yang et al., 2017; You, Dai, \& Wang, 2017; Yuan et al., 2019; L. S. Zhang et al., 2019).

Our best understanding of how mRNA modifications can influence gene expression comes from a long-standing body of work of inosine, and overlying the findings of transcriptome wide studies with genetic and biochemical investigations of $\mathrm{m}^{6} \mathrm{~A}$ (Bajad, Jantsch, Keegan, \& O'Connell, 2017; S. Schwartz, 2016). Inosine can contribute to mRNA stability, splicing, and translational recoding (Bazak et al., 2014; Ferreira et al., 2016; Garrett \& Rosenthal, 2012; Licht et al., 2019; Peng et al., 2018; Ramaswami et al., 2013; Rueter, Dawson, \& Emeson, 1999). Similarly, the primary consequence of $\mathrm{m}^{6} \mathrm{~A}$ is mRNA degradation, though effects on transcript maturation and translation have also been reported (Ke et al., 2017; Pendleton et al., 2017; X. Wang et al., 2014; Xiao et al., 2016; X. Zhao et al., 2014). Eukaryotes possess a series of "reader" and "eraser" proteins that bind $\mathrm{m}^{6} \mathrm{~A}$-containing transcripts to mediate these effects (Patil, Pickering, \& Jaffrey, 2018; Rajecka, Skalicky, \& Vanacova, 2019; S. Schwartz, 2016; H. Shi, Wei, \& He, 2019). Inosine prevalence and the conservation of $\mathrm{m}^{6} \mathrm{~A}$ reader proteins across a variety of eukaryotic species suggest that at least some modifications could contribute to biological function. Despite our in-depth knowledge of where mRNA modifications can exist and 


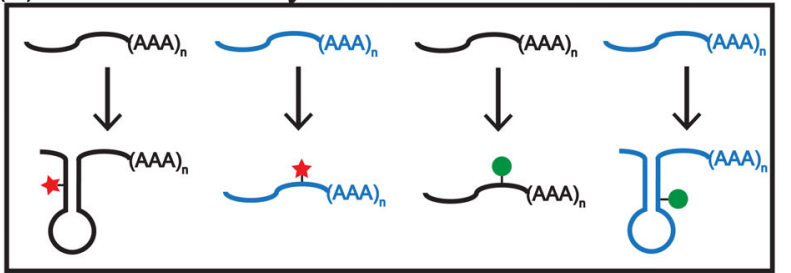

(b) Target selection

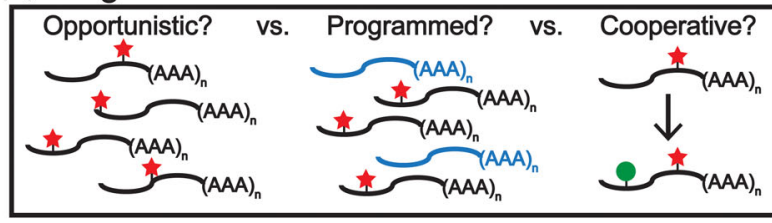

Biological significance

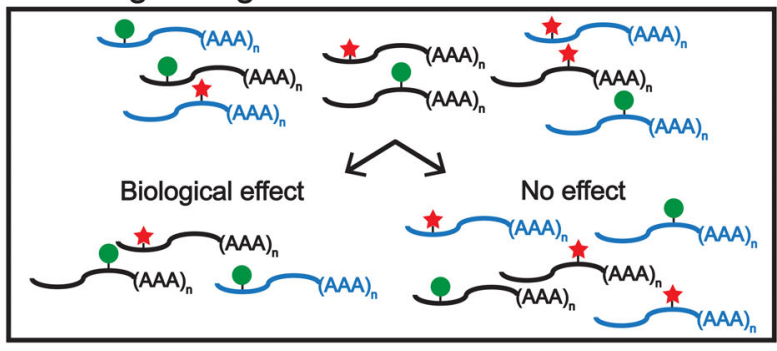

(d) Temporal effects

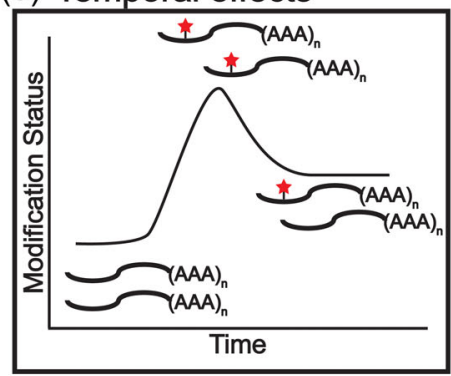

(e) Biological consequences

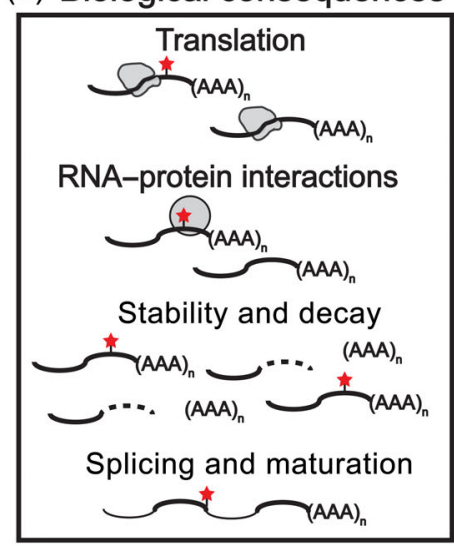

FI G U RE 3 The implementation of quantitative approaches will allow us to critically assess some of the key questions in the epitranscriptome field and establish a molecular understanding of individual messenger RNA (mRNA) modifications. Here, we present several knowledge gaps that we think can be best filled using quantitative approaches: (a) Several mRNA modifications, $\mathrm{m}^{6} \mathrm{~A}, \mathrm{~m}^{1} \mathrm{~A}, \mathrm{~m}^{1} \mathrm{G}, \Psi$, and $\mathrm{f}^{5} \mathrm{C}$, affect the stability of RNA secondary structure, but limited knowledge is known about the effect of other chemical modifications (Charette \& Gray, 2000; D. R. Davis, 1995; B. Liu et al., 2018; Roost et al., 2015; Spitale et al., 2015; R. Wang et al., 2016; Zhou et al., 2016). High-resolution structural biology and secondary structure-probing techniques are needed to uncover modification mediated structural changes. (b) Current transcriptome wide sequencing approaches have uncovered thousands of modification sites, but little is known about how modification insertion sites are selected. Modifications could be randomly incorporated on available sites, incorporated on specific locations of target transcripts, or there could be cross talk between sites on a single transcript (cooperative incorporation). Kinetic and thermodynamic investigations of modifying enzyme selectivity and broad analyses of the contributions of structure to selectivity (as in Carlile et al., 2019), coupled with measurements of the stoichiometry of multiple modifications on individual transcripts can help to distinguish between these models. (c) Targeted approaches will be required to discern which mRNA modification sites are biologically relevant. Measurements of modification stoichiometry, and assessment of how the stoichiometry at individual sites varies as a function of cell cycle, environment and disease is one example of experiments that could be done to identify significant sites of modification.

(d) Occupancy of individual sites might be temporally controlled, and therefore the stoichiometry of individual sites need to be quantitatively assessed as a function of time. Without this information it is likely that biologically relevant sites may be overlooked. (e) It is difficult to deconvolute the impact of mRNA modifications on mRNA-protein, splicing, mRNA stability, and mRNA translation on protein output in cells (see Figure 1). Reconstituted systems are ideally suited to overcome this challenge by allowing researchers to dissect how each individual interaction is influenced by mRNA modifications. These sorts of studies can help to establish which biological processes are likely more impacted by particular modifications, and have the potential to suggest likely consequences of mRNA modifications

growing molecular-level insight into inosine and $\mathrm{m}^{6} \mathrm{~A}$ function, we have a limited (or no) picture of the biological role for the other 14 reported mRNA modifications.

Establishing a quantitative, biochemical framework for understanding individual mRNA modifications to complement existing transcriptome wide datasets is one of the next milestones for the epitranscriptome field. In particular, measurements of the frequency (stoichiometry) of individual modification sites under a variety of cellular conditions and disease states will be required to determine which sites are the most biologically meaningful. Additionally, in vitro structural, thermodynamic, and kinetic studies characterizing how interactions between proteins, ncRNAs, decay machinery, and the ribosome are changed by mRNA modifications will provide a deep understanding of how posttranscriptional modifications can influence protein production. Such work can also potentially reveal additional 
functions of modifications that might not be immediately obvious from correlative studies. Together, these data will enable us to critically consider some of the key questions in the emerging epitranscriptome field-including assessing the potential biological significance/insignificance of individual modifications and modification sites (Figure 3). Here, we will discuss the pioneering studies starting to build a molecular foundation basis for understanding the epitranscriptome. We will focus on studies of modifications other than inosine, as adenosine to inosine (A to I) editing has been extensively reviewed elsewhere (Nishikura, 2016; Walkley \& Li, 2017; Y. Wang, Zheng, \& Beal, 2017). This review will emphasize the work conducted to quantify modification abundance, frequency of incorporation, and interactions with the cellular machinery.

\section{2 | QUANTITATIVE APPROACHES FOR STUDYING MRNA MODIFICATION LEVELS AND CONSEQUENCES}

We will begin by presenting and contextualizing some of the quantitative approaches used to characterize mRNA modifications. In particular, we will discuss methods that measure mRNA levels and stoichiometries to quantitatively describe the mRNA modification landscape of the transcriptome. Additionally, we will highlight a variety of approaches that provide insight into the biological consequences of mRNA modifications by evaluating the impact of modifications on mRNA:protein interactions, splicing, translation and decay.

\section{1 | Liquid chromatography with tandem mass spectrometry (LC-MS/MS) measures total modification abundance}

The overall abundance of modifications is an important metric for gauging how broadly a particular modification might influence mRNAs. Sequencing strategies have provided deep insight into where mRNA modifications can be localized. However, sequencing-based approaches cannot reliably report on absolute modification abundances because they rely heavily on the efficiency and specificity of the biochemical workflow as well as the bioinformatic parameters used to analyze the data (peak alignment, peak detection method, etc.; Helm \& Motorin, 2017). Direct methods, such as LCMS/MS, are better suited to measure the overall abundance of modifications in mRNAs. LC-MS/MS is a wellestablished approach extensively utilized to quantify post-transcriptional modifications in ncRNAs including tRNAs and rRNAs and is increasingly being applied to study mRNA modifications.

In order to measure modification levels by LC-MS/MS, mRNAs are purified and enzymatically hydrolyzed to mononucleosides (Chan et al., 2010; Kowalak, Pomerantz, Crain, \& McCloskey, 1993; Pomerantz \& Mccloskey, 1990; Russell \& Limbach, 2013; Su et al., 2014). The resulting nucleosides are separated using liquid chromatography (LC) and absolutely quantitated by mass spectrometry using multiple reaction monitoring with an internal standard. Early studies used LC-MS/MS to confirm the presence of mRNA modifications found by RNA-seq, but more recently researchers have begun to use LC-MS/MS to identify new modifications and modifying enzymes (Chu et al., 2018; Tardu et al., 2019; Xu et al., 2017). Additionally, high-throughput applications of LC-MS/MS for mRNA modification discovery and characterization are emerging. These approaches are similar to mass spectrometry studies of tRNA modifications that characterize dozens of nucleosides in parallel and allow researchers to rapidly explore a broad chemical space (Chu et al., 2018; Su et al., 2014; Tardu et al., 2019; Xu et al., 2017). Nonetheless, the impact of current LC-MS/ MS approaches is limited because they do not provide any sequence context for modified nucleosides and require large quantities of highly purified mRNA.

\section{2 | Approaches for measuring modification occupancy}

Determining the occupancy of discrete mRNA modification sites is imperative for uncovering the contributions of modifications to biological processes. If modifications serve as a gene regulatory mechanism, then the occupancy of controlled modification sites is likely to vary over the lifetime of an mRNA to alter its function (Figure 3). Transcriptome wide methodologies to measure site occupancy will allow us to form hypotheses about which modified sites may influence biological processes. This is especially true in the context of stress or diseased states, under which modification occupancy levels could dramatically fluctuate. Comparison of the absolute abundances of mRNA modifications with 
the number of possible sites of modification indicates that the occupancy of most modification sites are likely sub-stoichiometric, similar to protein post-translational modifications (PTMs; Prus, Hoegl, Weinert, \& Choudhary, 2019).

The occupancy of individual sites can be measured with site-specific cleavage and radioactive-labeling followed by ligation-assisted extraction and thin-layer chromatography (SCARLET) (N. Liu et al., 2013). SCARLET uses complementary oligos targeted to known modification sites to investigate the occupancy of the modification at discrete sites. This method takes advantage of the different chemical properties of modified and unmodified nucleosidesusing thin-layer chromatography to separate radioactively labeled modified/unmodified RNA species in a manner that enables the quantification of the relative modification frequency (described in detail in Figure 4). Notably, because SCARLET does not rely on the specific recognition of a modification by an antibody or nuclease, it can be applied to all modifications. While SCARLET is a highly accurate method for quantifying the extent of modification incorporation in mRNAs, it requires researchers to know where modification sites exist, can only assess a single site at a time, and is challenging to implement. As such, despite being the first and arguably most reliable method of quantifying mRNA modification occupancy, SCARLET has only been applied to study a handful of $\mathrm{m}^{6} \mathrm{~A}$ sites, and a single $\Psi$-modified mRNA (Chen et al., 2015; Duan et al., 2017; X. Li et al., 2015; Linder et al., 2015; N. Liu et al., 2013; Y. Zhao, Karijolich, Glaunsinger, \& Zhou, 2016).

Reliable approaches for measuring the transcriptome wide occupancy of mRNA sites only exist for studying $\mathrm{m}^{6} \mathrm{~A}$ and inosine (Sakurai et al., 2014; Zaccara, Ries, \& Jaffrey, 2019). For the purposes of this review, we will focus on $\mathrm{m}^{6} \mathrm{~A}$ related methods, $\mathrm{m}^{6} \mathrm{~A}$-level and isoform-characterization sequencing $\left(\mathrm{m}^{6} \mathrm{~A}\right.$-LAIC-seq) and $\mathrm{m}^{6} \mathrm{~A}$-sensitive RNA digestion and sequencing (MAZTER-seq; Figure 4), as inosine methods are well reviewed in Sakurai et al. (2014), Garcia-Campos et al. (2019), and Molinie et al. (2016). MAZTER-seq and $\mathrm{m}^{6} \mathrm{~A}$-LAIC-seq use either an antibody or nuclease to identify modified sites in purified cellular RNA and synthetic mRNA controls. RNA-seq is subsequently used to measure the abundance of both mRNAs of interest and the controls to determine $\mathrm{m}^{6} \mathrm{~A}$ incorporation frequency. These methods, while powerful, both rely on indirect methods to detect the $\mathrm{m}^{6} \mathrm{~A}$ modification. The recent advent of direct nanopore ion sequencing technology may eventually permit researchers to directly measure the occupancy of all modifications on individual mRNA transcripts, but further advances in the computational analysis of nanopore data will be required before this approach can be widely implemented for this purpose (Jain, Olsen, Paten, \& Akeson, 2016).

\section{3 | Transcriptome wide studies of mRNA translation and half-life}

Sequencing-based approaches have been used to assess both the half-life and translation of modified mRNAs transcriptome wide. Ribosome profiling is a powerful technique that allows researchers to take a snap-shot of where every ribosome sits on every mRNA in a cell at a given period of time (Ingolia, Ghaemmaghami, Newman, \& Weissman, 2009). This approach enables the identification of well- and poorly-translated sequences in vivo, and can even provide insight into how distinct states of translation elongation are modulated (Lareau, Hite, Hogan, \& Brown, 2014; C. C. Wu, Zinshteyn, Wehner, \& Green, 2019). Similarly, the half-lives of all cellular mRNAs can be measured in parallel by using RNA-seq to observe the time-dependent reductions in mRNA levels following transcriptional shut-off by small molecules, such as actinomycin, or temperature sensitive RNA Polymerase II mutants (Lugowski, Nicholson, \& Rissland, 2018). Ribosome profiling and transcriptome wide half-life measurements robustly report on the details of mRNA stability and translation and have greatly advanced our understanding of RNA biology.

Utilizing ribosome profiling and transcriptome wide decay studies to discern the function of a specific modification would ideally involve knocking-out (or knocking-down) an mRNA modifying enzyme, and comparing the translation and stability of modified and unmodified mRNAs. It is important to note that ribosome profiling and transcriptome wide half-life studies report on the average behavior of the overall population of mRNA transcripts containing a given sequence. Therefore, the heterogeneity of modification occupancy introduces challenges for interpreting data collected by these methods. The analysis of such data is further complicated by the fact that most enzymes that catalyze mRNA modification also catalyze the incorporation of the same functional groups into ncRNA species essential to protein translation (e.g., tRNAs, ribosomal RNA [rRNA]; Arango et al., 2018; X. Li et al., 2017; S. Schwartz et al., 2014; Tardu et al., 2019; Xu et al., 2017). Since translation and decay rates are coupled, these potential perturbations to the translation machinery can make complicate efforts to deconvolute the impacts of modifications on ncRNAs from those on mRNAs by these methods (Figure 1; Presnyak et al., 2015; Radhakrishnan et al., 2016). Ultimately, regardless of their limitations, ribosome profiling and transcriptome wide mRNA half-life studies will be useful for uncovering how 

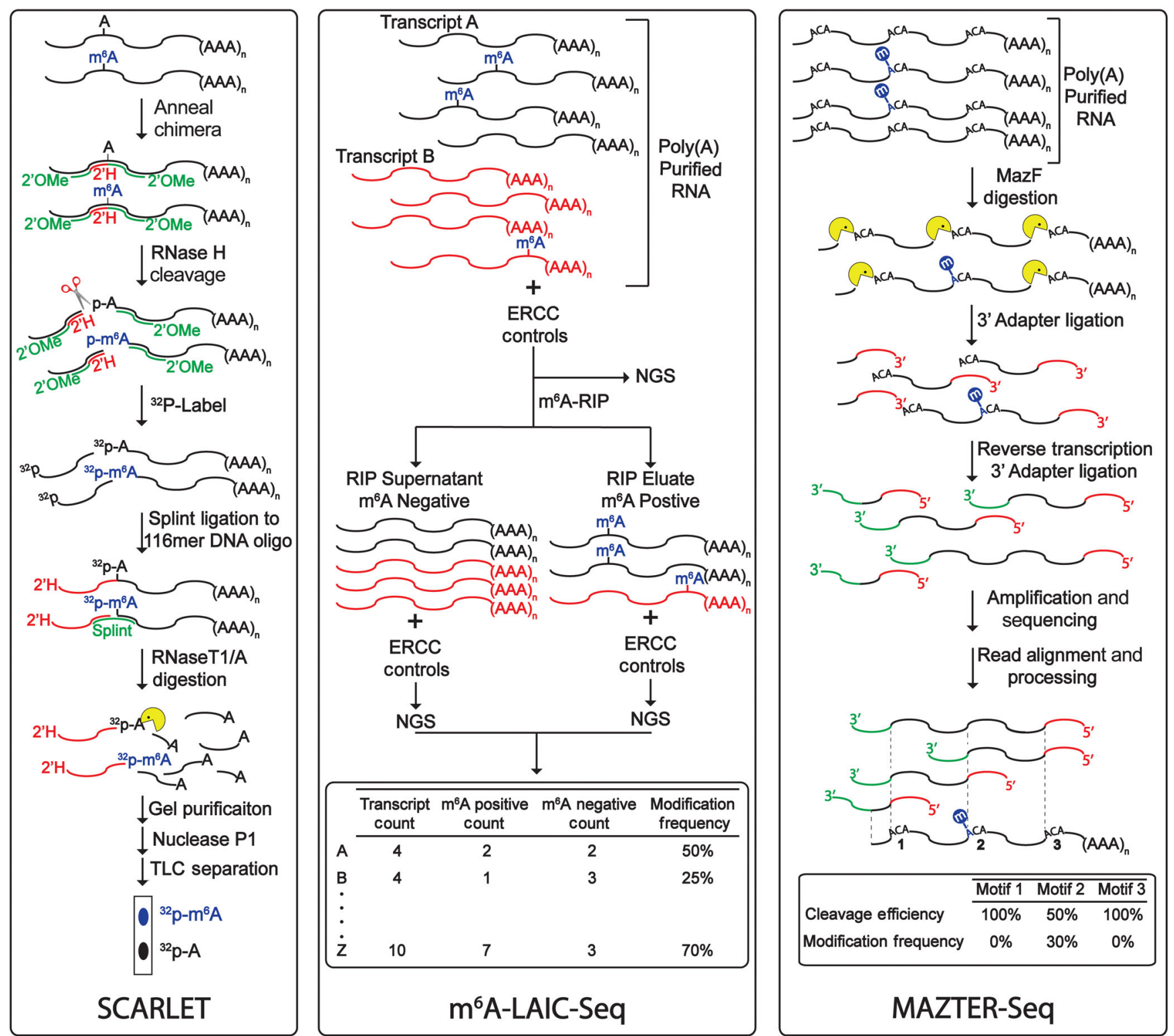

F I G U R E 4 Methods to quantify messenger RNA (mRNA) m6 modification stoichiometry. (a) Site-specific cleavage and radioactivelabeling followed by ligation-assisted extraction and thin-layer chromatography (SCARLET) is the most direct method developed to quantify $\mathrm{m}^{6} \mathrm{~A}$ frequency (N. Liu et al., 2013). During this process, a chimera is annealed to a specific mRNA where the DNA sequence is immediately upstream of the putative modification site. RNase $\mathrm{H}$ is used to cleave the mRNA to release an oligonucleotide containing the putative modification at the $5^{\prime}$ end. The $5^{\prime}$ end of the oligonucleotide is ${ }^{32} \mathrm{P}$-labeled using T4 polynucleotide kinase and is splint ligated to a 116mer DNA oligomer. RNase T1/A is used to digest the resulting chimera to contain a single $\mathrm{A}$ or $\mathrm{m}^{6} \mathrm{~A}$ at the $3^{\prime}$ end of the $116 \mathrm{mer}$ DNA oligomer. The resulting oligonucleotide is gel purified, digested to nucleosides using nuclease P1, and analyzed using TLC. The stoichiometry is measure based on the relative intensity of the $\mathrm{m}^{6} \mathrm{~A}$ and A phosphorescence. (b) $\mathrm{m}^{6} \mathrm{~A}$-level and isoform-characterization sequencing ( $\mathrm{m}^{6} \mathrm{~A}$-LAIC-seq; Molinie et al., 2016) utilizes $\mathrm{m}^{6} \mathrm{~A}$ modified external RNA controls consortium (ERCC) control RNAs to normalize the measured $\mathrm{m}^{6} \mathrm{~A}$ stoichiometries to increase the accuracy of a standard $\mathrm{m}^{6} \mathrm{~A}$-RIP assay. ERCC controls are added before and after $\mathrm{m}^{6} \mathrm{~A}$-RIP to normalize the efficiency of the immunoprecipitation and detection by next generation sequencing, respectively. The relative counts of $\mathrm{m}^{6} \mathrm{~A}$ positive and negative reads of the same transcript determine the stoichiometry. The occupancy levels measured by $\mathrm{m}^{6} \mathrm{~A}$-LAIC-seq correlate well with modification levels of mRNA standards $(R=0.995)$ despite the lack of single nucleotide resolution. (c) MAZTER-seq also utilizes RNA-seq to characterize $\mathrm{m}^{6} \mathrm{~A}$ occupancy transcriptome wide (Garcia-Campos et al., 2019). However, MAZTER-seq does not rely on immunoprecipitation to isolate modified mRNAs, and instead identifies sites using the bacterial nuclease MazF to cleave immediately upstream of ACA sequences but not $\mathrm{m}^{6} \mathrm{ACA}$ sequences. Purified mRNA is digested using MazF, and an adapter is ligated to the $3^{\prime}$ end of the digested products. The resulting oligonucleotides are reverse transcribed, $3^{\prime}$ adapter ligated, amplified, and end-pair sequenced. Following read alignment and data processing, the stoichiometry is determined by calculating the cleavage efficiency of MazF at a specific ACA motif. While MAZTER-seq has the advantage of quantifying $\mathrm{m}^{6} \mathrm{~A}$ occupancy at single nucleotide resolution, there are some limitations to this approach. Namely, the lack of quantification at the $\sim 50 \%$ of $^{6} \mathrm{~A}$ found outside ACA motifs (Pandey \& Pillai, 2019), MazF only cuts at ACA sites with 70\% efficiency and can cleave at other sequences resembling ACA, and the values measured by MAZTER-seq only modestly correlate with SCARLET measurements at similar sites $(R$ values $=0.6-0.7$; Garcia-Campos et al., 2019) 
mRNA modifications change translation and mRNA stability, however, we anticipate that interpretation of transcriptome wide observations will benefit from synergistic in vitro studies.

\subsection{In vitro biochemistry and structural biology}

For over 70 years high-resolution structural and functional studies with purified cellular components have proven invaluable for our understanding of how biology controls the production, function and degradation of biomolecules. One of the fundamental principles of biochemistry is that the 3D structure of molecules determines their function. In general, much less is known about the structures of RNAs relative to proteins. This is evidenced by the fact that structures of RNA and RNA-protein complexes represent $<5 \%$ of the structures deposited in the Protein Data Bank (PDB) (Berman, Henrick, \& Nakamura, 2003). High-resolution X-ray crystallography, cryo-EM and NMR studies of modified mRNAs, modified mRNA-protein, and modified mRNA-ribosome complexes will be vital for building a detailed understanding of how modifications can influence mRNA structure (Choi et al., 2016; Eyler et al., 2019; Svidritskiy, Madireddy, \& Korostelev, 2016; Zhou et al., 2016). Additionally, lower resolution RNA-secondary structure mapping studies (e.g. using DMS or SHAPE reagents) comparing modified and unmodified mRNAs can provide additional insights information about how the shape of mRNAs is influenced by modifications (Mauger et al., 2019). Structural studies will prove useful not only for understanding how modifications impact the intrinsic properties of mRNAs to impact their function and stability, but also as researchers are seeking to develop therapeutics targeting $\mathrm{m}^{6} \mathrm{~A}$-modified transcripts (Cross, 2019).

Changes in mRNA structure, charge, or base-pairing ability can reasonably be expected to alter the interaction of these molecules with other biomolecules. Therefore, in vitro kinetic and thermodynamic assays will be required to establish how modifications alter mRNA interactions with proteins, other RNAs, or the ribosome (Choi et al., 2016; Eyler et al., 2019; Vaidyanathan, AlSadhan, Merriman, Al-Hashimi, \& Herschlag, 2017). Such studies are limited in their scale, but have the benefit of being readily interpretable. For example, in vitro translation assays on modified mRNAs have been used to directly report on how modifications alter the action of the translation machinery in a straightforward manner, without the needing to consider in rRNA or tRNA modification status or mRNA stability. Single molecule and bulk transient kinetic studies will allow us to establish how individual functional groups affect specific steps in the translation and decay pathways (Choi et al., 2016, 2018; Eyler et al., 2019). Given the critical contributions of fundamental biochemical and structural studies to our understanding essential biological processes, including posttranslational protein modifications, we anticipate that such studies will be vital as researchers begin to understand the types and extent of consequences of mRNA modifications on biology.

\section{3 | CURRENT QUANTITATIVE PERSPECTIVE ON MRNA MODIFICATIONS}

In order to evaluate the significance of post-transcriptional mRNA modifications, there are several fundamental questions that remain to be critically investigated (detailed in Figure 3). Here, we discuss how quantitative measurements are allowing researchers to begin addressing some of the key gaps in our knowledge of mRNA modifications. We will examine the available quantitative measurements of mRNA modification levels and incorporation frequency, and consider these findings in the context of post-translational protein modification stoichiometries. Additionally, we will discuss the insights into how mRNA modifications impact interactions between mRNAs and the cellular machinery provided by structural biology, in vitro biochemistry, and quantitative transcriptome wide studies. Together, these data suggest that several mRNA modifications are reasonably abundant, affect mRNA structure, and can influence how proteins and the ribosome interact with transcripts.

\subsection{I mRA modification abundance and frequency}

As we begin to investigate the consequences and potential biological functions of mRNA modifications, it seems reasonable to first consider where and how frequently they are present. The levels of different mRNA modifications vary widely; there is a $>1,000$-fold range in concentrations for the mRNA modifications levels measured to date (Table 1 and Figure 5). $\mathrm{m}^{6} \mathrm{~A}$ is the most abundant modification across all organisms (Table 1), as might be expected given its 
F I G U RE 5 LC-MS/MS measurements of mRNA modification abundance. All values displayed are the average values for mammals unless indicated otherwise (* yeast, ** plant) (Table 1). The error bars reflect the range of values measured. Modifications without error bars have only one reported value in the literature

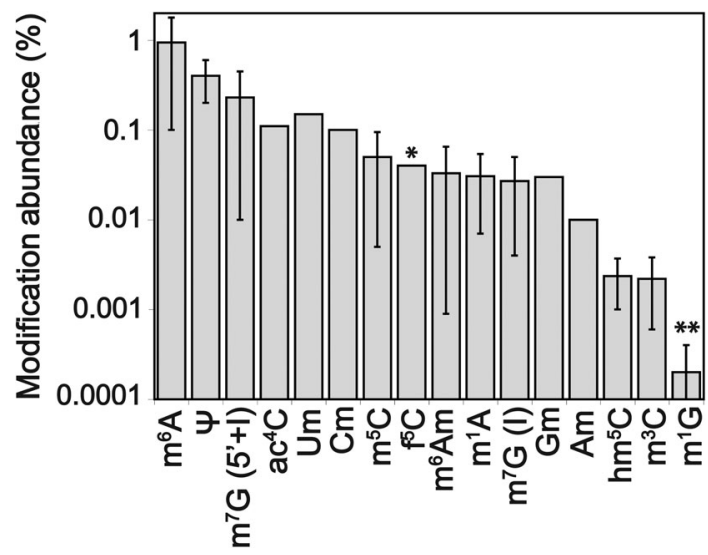

purported widespread role in the post-transcriptional regulation of a host of mRNAs. SCARLET, $\mathrm{m}^{6} \mathrm{~A}$-LAIC-seq and MAZTER-seq established a wide range of $\mathrm{m}^{6} \mathrm{~A}$ frequencies (0-95\%) at mapped sites (Chen et al., 2015; Duan et al., 2017; Garcia-Campos et al., 2019; X. Li et al., 2015; Linder et al., 2015; Y. Zhao et al., 2016). Transcriptome wide analyses of $\mathrm{m}^{6} \mathrm{~A}$ site occupancies revealed a nearly bimodal distribution of $\mathrm{m}^{6} \mathrm{~A}$ frequency (centered around $\sim 10 \%$ and 50-60\%), and demonstrate that $\mathrm{m}^{6} \mathrm{~A}$ modification frequencies differ on the same transcripts between GM12878, HEK293T, and hESC cells. ${ }^{6}$ A modifications are enriched in mRNA 3' UTRs and near stop codons (Dominissini et al., 2012; Meyer et al., 2012). Notably, the presence of m6A in 3' UTRs opens up the possibility that m6A could be incorporated into some miRNA target sites to modulate miRNA-binding. Regardless of where they are localized, the data suggest that $\mathrm{m}^{6} \mathrm{~A}$ sites are essentially never fully occupied on any given transcript, making it unlikely that modifications serve as a binary switch to dictate the maturation, movement or behavior of the entirety of mRNA molecules of any particular sequence.

Several modifications, $\Psi, \mathrm{ac}^{4} \mathrm{C}, \mathrm{Cm}$, and $\mathrm{Gm}$, have abundances approaching those of $\mathrm{m}^{6} \mathrm{~A}$ (Arango et al., 2018; $\mathrm{X}$. Li et al., 2015; Tardu et al., 2019; You et al., 2017). These modifications have been less well studied than $\mathrm{m}^{6} \mathrm{~A}$, but their prevalence and localization in mRNA coding regions suggests that they might also play roles in regulating mRNA function (Arango et al., 2018; Carlile et al., 2014; X. Li et al., 2015; Lovejoy et al., 2014; Nakamoto, Lovejoy, Cygan, \& Boothroyd, 2017; S. Schwartz et al., 2014; L. Sun et al., 2019; You et al., 2017). Like $\mathrm{m}^{6} \mathrm{~A}$, the positions of some of these modifications appear to be conserved. For example $\Psi$ is most commonly found in the second and third position of UUU and second position of UUC codons in protozoa, plant and human mRNA coding regions (Nakamoto et al., 2017; S. Schwartz et al., 2014; L. Sun, Xu, et al., 2019). Little is known about how often modifications other than $\mathrm{m}^{6} \mathrm{~A}$ or inosine are incorporated at particular mRNA sites. However, estimates of $\Psi$-frequency based on $\Psi$-seq experiments suggest that $\Psi$ incorporated into mRNA by pseudouridine synthase 7 (Pus 7) is present at high levels; with a distribution occupancy comparable to ribosomal RNA (rRNA) levels (S. Schwartz et al., 2014). Furthermore, SCARLET measurements of $\Psi$ occupancy in EEF1A1 mRNA are consistent with this conclusion- $\Psi$ is present in $56 \%$ of the time in this transcript, a frequency comparable to many of the reported $\mathrm{m}^{6} \mathrm{~A}$ and inosine sites (X. Li et al., 2015; Sakurai et al., 2014). Together these data suggest that the incorporation frequency of $\Psi$, at least at some sites, is likely to be high.

Most modifications are present at levels 10- to 100 -fold less than $\mathrm{m}^{6} \mathrm{~A}$, and a handful of modifications $\left(\mathrm{m}^{3} \mathrm{C}, \mathrm{m}^{1} \mathrm{G}\right.$, $\mathrm{hm}^{5} \mathrm{C}$ ) are even more rare, with levels at least 500-fold lower than $\mathrm{m}^{6} \mathrm{~A}$ (Figure 5, Table 1). The location of $\mathrm{m}^{5} \mathrm{C}$ modifications have been mapped primarily to mRNA $5^{\prime}$ UTRs, and the relative occupancy of $\mathrm{m}^{5} \mathrm{C}$ sites has also been estimated using a stringent bisulfite sequencing method (Amort et al., 2017; T. Huang, Chen, Liu, Gu, \& Zhang, 2019). While incomplete conversion of cytidine and $\mathrm{m}^{5} \mathrm{C}$ during bisulfite treatment limits the accurate quantification and location of $\mathrm{m}^{5} \mathrm{C}$ throughout the transcriptome, control RNAs were utilized to tune treatment conditions and approximate $\mathrm{m}^{5} \mathrm{C}$ modification frequency $\left(R^{2}=0.98\right)$ and location. This study suggests that $\mathrm{m}^{5} \mathrm{C}$ occupancy at most sites is low $(<20 \%)$ relative to $\mathrm{m}^{6} \mathrm{~A}$ and $\Psi$, as might be expected from the modest levels of $\mathrm{m}^{5} \mathrm{C}$ measured in mRNAs by LC-MS/MS (Figure 5). The modest levels of the majority of modifications suggest that the enzymes responsible for these modifications likely either target only a handful of specific mRNAs targets, as studies indicate is the case for $\mathrm{m}^{1} \mathrm{~A}$, or might modify many different mRNAs at relatively low frequencies (Khoddami et al., 2019; Safra et al., 2017). Alternatively, it is possible that the levels of these modifications have just not been measured yet under conditions where the modification is most highly incorporated. We expect to find other relatively rare mRNA modifications, such as $\mathrm{m}^{3} \mathrm{C}$ and $\mathrm{m}^{1} \mathrm{G}$, may also exhibit low occupancy at many (though perhaps not all) of their sites. 
T A B LE 1 Summary of modification abundances measured by targeted liquid chromatography with tandem mass spectrometry (LC-MS/MS)

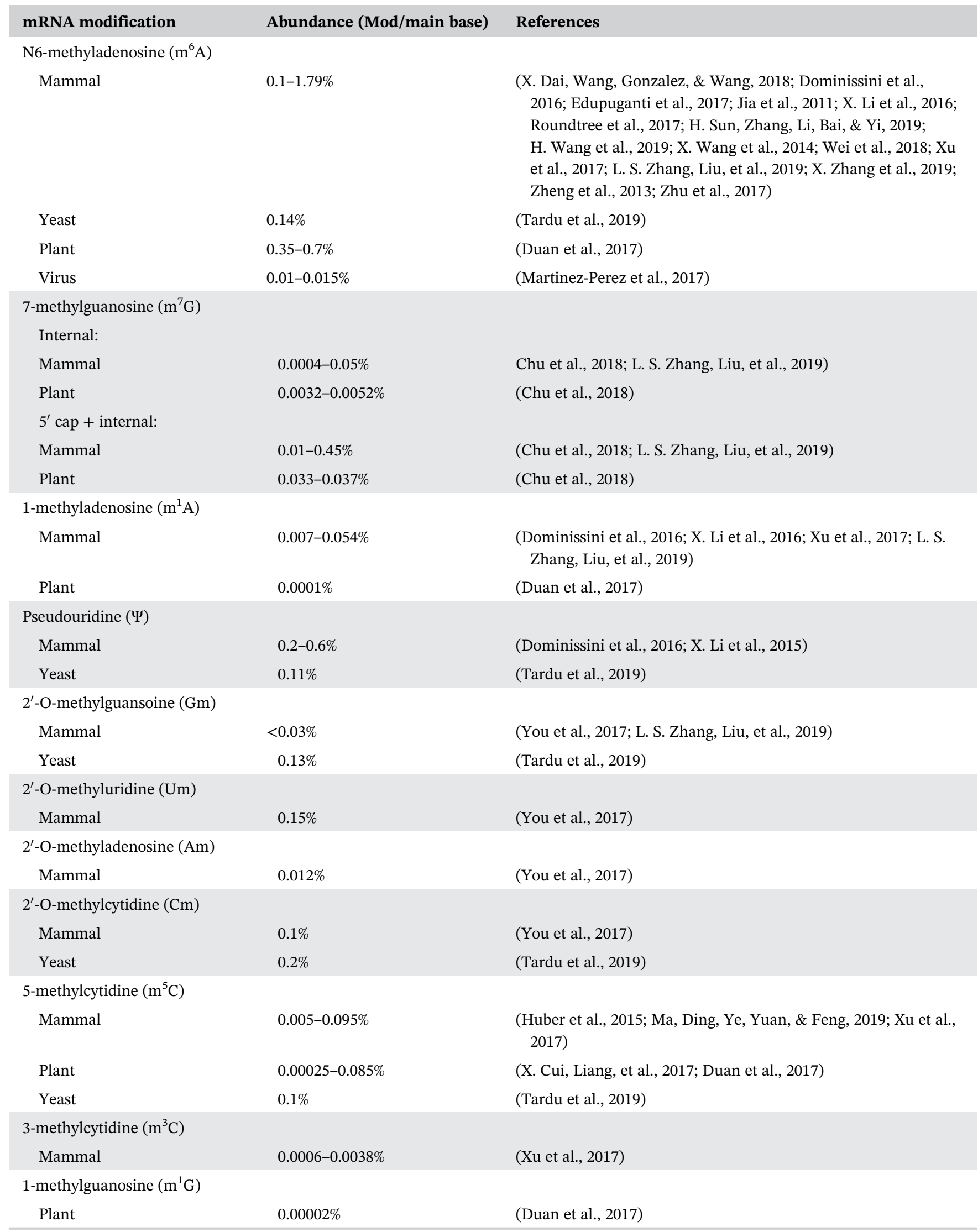


TABLE 1 (Continued)

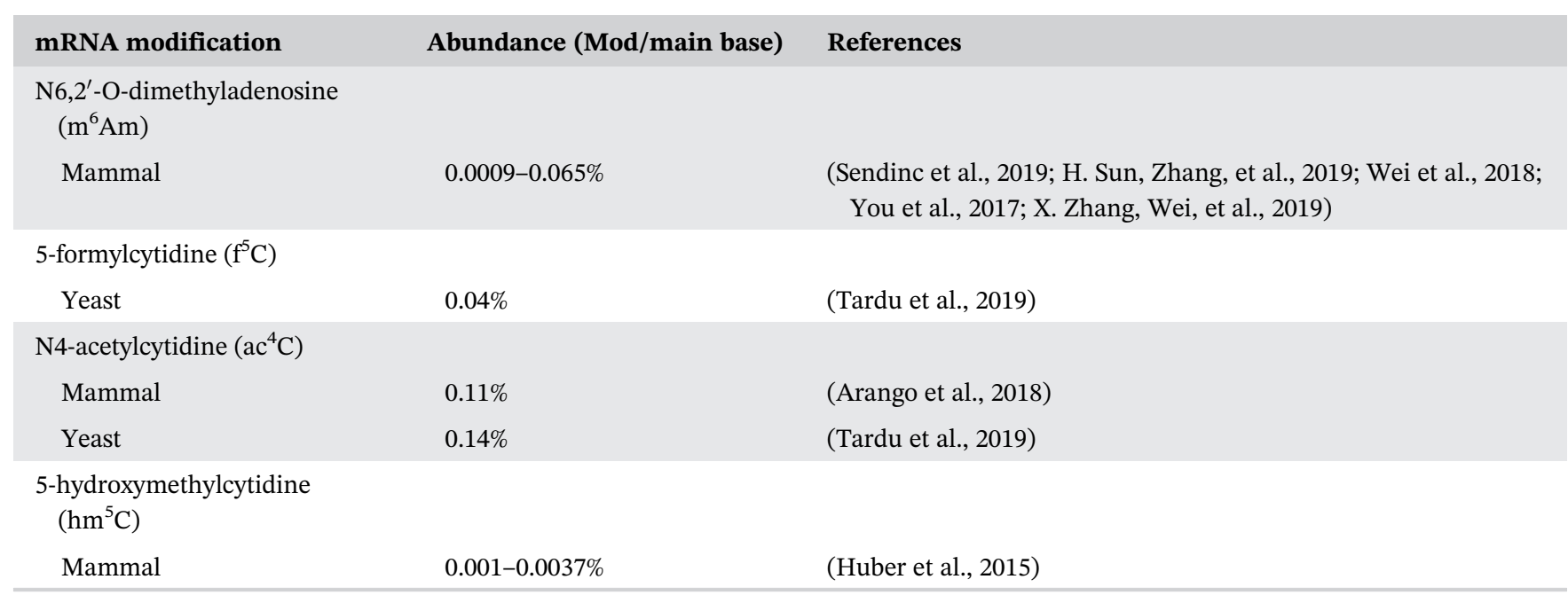

Notes: The values reported are the abundance of a modification with respect to its unmodified nucleoside (e.g., $\mathrm{m}^{6} \mathrm{~A} / \mathrm{A}$, $\mathrm{m}^{7} \mathrm{G} / \mathrm{G}$, etc.) within purified messenger RNAs (mRNAs). The modification abundances range over 500-fold from $\mathrm{m}^{6} \mathrm{~A}$ (the most abundant modification), which displays the potential complexity of how different variants affect the mRNA life cycle. We have displayed the reported mRNA modifications that have been quantified in multiple cell types and tissues (mammalian, yeast, plant, and viral). Moreover, levels of both internal and $5^{\prime}$-cap plus internal $\mathrm{m}^{7} \mathrm{G}$ have been quantified using alternative enzymatic digestion strategies.

It is important to note that just because sites are not well occupied in a given transcriptome wide snap-shot, this does not necessarily mean that they are insignificant. PTMs are also typically sub-stoichiometric, and their frequency varies from site to site and in response to cellular conditions (Prus et al., 2019). For example, protein acetylation occurs at a wide range of stoichiometries $(<1-98 \%)$, with bulk of protein acetylation sites exhibiting very low modification frequencies (<1\%) (Baeza et al., 2014; Hansen et al., 2019; Weinert et al., 2015). In contrast, sites of phosphorylation tend to be occupied at a modestly higher levels (>20\%) (Carpy et al., 2014; Olsen et al., 2010; Tsai et al., 2015; R. Wu et al., 2011), while N-glycosylation sites are frequently occupied (>60\%) (S. Sun \& Zhang, 2015; Zielinska, Gnad, Wisniewski, \& Mann, 2010). Despite the wide distribution of PTM stoichiometries, they each significantly impact the regulation of protein biology. This highlights the need to extensively characterize mRNA modifications despite the substoichiometric modification of sites.

Furthermore, occupancy of sites might be temporally controlled so that they are only impactful at a particular time (Figure 3). In ncRNAs, nucleoside levels dynamically fluctuate in response to environmental stress, nutrient deprivation, stages in circadian rhythms, and cell cycle progression to alter RNA function (Baudin-Baillieu et al., 2009; Demirci et al., 2010; Helm \& Alfonzo, 2017; Maraia \& Arimbasseri, 2017; Sergiev, Aleksashin, Chugunova, Polikanov, \& Dontsova, 2018). Analysis of mRNA modification abundances under different conditions may provide insight into modification-mediated mechanisms activated by environmental stress or disease. Consistent with this possibility, both the abundances and distributions of mRNAs modifications are dependent on environmental conditions, cell-type, disease, and organism (Table 1; Carlile et al., 2014; Chu et al., 2018; X. Cui, Liang, et al., 2017; Duan et al., 2017; X. Li et al., 2016; Ma et al., 2019; S. Schwartz et al., 2014; Tardu et al., 2019; Zhou et al., 2015). Nucleoside methylations and acetylations exhibit the largest changes in mRNA modification abundance as a result of shifting cellular environments (Tardu et al., 2019). In line with this observation, the metabolites used by enzymes to catalyze methyl- and acetyl- modifications (S-adenosylmethionine and acetyl-CoA) also fluctuate significantly in response to cellular conditions (Anstee \& Day, 2012; Pietrocola, Galluzzi, Bravo-San Pedro, Madeo, \& Kroemer, 2015; L. Shi \& Tu, 2015). Comprehensive studies of modification frequency under varied cellular conditions, disease states, and time points will be necessary to uncover this information and link sites more directly to function (Figure 3).

\section{2 | Consequences of mRNA modifications on translation}

The functional role of mRNAs in the cell is to serve as blueprints for protein synthesis. As such the translational machinery surely encounters modified mRNAs. Most mRNA modifications have been observed throughout mRNAs, 
and the preponderance of $\Psi, \mathrm{ac}^{4} \mathrm{C}$ and $2^{\prime} \mathrm{O}$-methyl modifications are found in mRNA coding regions (Arango et al., 2018; Carlile et al., 2014; Q. Dai et al., 2017; Nachtergaele \& He, 2017; Nakamoto et al., 2017; S. Schwartz et al., 2014; You et al., 2017). Modifications have the potential to change how the ribosome interprets the mRNA blueprint because they can alter the hydrogen bonding interactions between codons and aminoacylated-tRNAs. This possibility is supported by decades of observations indicating that tRNA anticodon nucleobase modifications alter mRNA:tRNA interactions to influence ribosome speed and fidelity (Fan et al., 2017; Fan et al., 2015; Pan, 2018; Phizicky \& Hopper, 2015; Ranjan \& Rodnina, 2017; M. H. Schwartz \& Pan, 2016). However, deciphering the impact of mRNA modifications on translation in biological systems has been challenging for a number of reasons. Foremost amongst these is the fact that most enzymes that catalyze mRNA modification also catalyze the incorporation of the same functional groups into ncRNA species essential to protein translation (e.g., tRNAs, ribosomal RNA [rRNA]; Arango et al., 2018; X. Li et al., 2017; S. Schwartz et al., 2014; Tardu et al., 2019; Xu et al., 2017). The shared origin of many coding and ncRNA modifications has limited the utility of classical genetics to discern mRNA modification function. Furthermore, the heterogeneity in modification occupancy makes it difficult for researchers to directly observe translation of modified transcripts in vivo. Last, it can be problematic to fully deconvolute the impact of translation from protein- and mRNA-stability on protein output in cells. Illustrative of this, reporter-based studies have reached conflicting conclusions regarding how several modifications influence translation (Dominissini et al., 2016; Grozhik \& Jaffrey, 2018; Hoernes, Clementi, et al., 2016; Hoernes et al., 2019; Karijolich \& Yu, 2011; Svidritskiy et al., 2016). Therefore, for the purpose of this review, we will focus on discussing in vitro studies with reconstituted translation systems that offer a way to directly assess how modifications impact ribosome function.

Initial in vitro studies of varying resolution on a limited set of mRNA modifications indicate that modifications can alter the overall rate and fidelity of protein synthesis (Choi et al., 2016, 2018; Eyler et al., 2019; Hoernes, Clementi, et al., 2016; Hoernes et al., 2018, 2019; Hudson \& Zaher, 2015; You et al., 2017). In fully reconstituted Escherichia coli translation systems, naturally occurring enzymatic nucleoside modifications and damaged ribonucleobases change translation to varying degrees (Figure 6). The overall level of reporter peptides produced from mRNAs containing a single modified nucleobase is reduced by 2- to $>50$-fold for $\mathrm{m}^{6} \mathrm{~A}, \Psi, \mathrm{Cm}, \mathrm{Am}, \mathrm{m}^{1} \mathrm{~A}, \mathrm{~m}^{6} \mathrm{G}$ and $\mathrm{m}^{1} \mathrm{G}$, and is essentially unchanged for $\mathrm{m}^{5} \mathrm{C}$ (Hoernes, Clementi, et al., 2016; You et al., 2017). The severity of the protein expression defect is highly dependent on the location of the modification within a codon - protein outputscan range by $>25$-fold depending on the position of a modification within a single codon (Hoernes, Clementi, et al., 2016; You et al., 2017). The effects observed in $E$. coli have been recapitulated in eukaryotic wheat germ extract translation assays, where $\mathrm{m}^{6} \mathrm{~A}, \mathrm{~m}^{1} \mathrm{~A}$, and $\mathrm{m}^{1} \mathrm{G}$ were shown to reduce the production of a reporter peptide in a position dependent manner (You et al., 2017). Notably, in contrast to findings in E. coli, $\mathrm{m}^{6} \mathrm{G}$ also appeared to both impede and enhance protein output in wheat germ extacts depending on where it was localized within a modified codon.

Further elegant bulk and single-molecule mechanistic investigations of $2^{\prime} \mathrm{O}$-methyl, $\mathrm{m}^{6} \mathrm{~A}, \Psi$, and $\mathrm{m}^{6} \mathrm{G}$ modifications reveal that these modifications impact multiple steps in the ribosome kinetic pathway, reducing the rate of peptide bond formation and guanosine-5'-triphosphate hydrolysis by EF-Tu (Choi et al., 2016, 2018; Eyler et al., 2019; Hudson \& Zaher, 2015). $2^{\prime}$ O-methylmodifications and $\mathrm{m}^{6} \mathrm{~A}$ have been further shown to impede tRNA accomodation-a crucial step in translation elongation (Choi et al., 2016, 2018). Crystal structures of the 30S Thermus thermophilus ribosome bound to $\mathrm{m}^{6} \mathrm{~A}$-modified mRNAs, and the $70 \mathrm{~S}$ ribosome on a $\Psi$-modified mRNA indicate that $\mathrm{m}^{6} \mathrm{~A}$ and $\Psi$ can still form Watson-Crick base pairs with cognate tRNAs (Choi et al., 2016; Eyler et al., 2019). The structure of the 70S ribosome with tRNA ${ }^{\text {Phe }}$ bound to $\Psi \mathrm{UU}$ in the A site further demonstrates that despite the presence of correct mRNA:tRNA basepairing interactions, the $3^{\prime} \mathrm{CCA}$ of $\mathrm{TRNA}^{\mathrm{Phe}}$ is not properly positioned in the peptidyl-transfer center (PTC) of the ribosome, consistent with the kinetic observations suggesting that $\Psi$ changes translation (Eyler et al., 2019). Together, these studies indicate that mRNA modifications tend to slow the ribosome and that the magnitude to which a modification perturbs translation depends strongly on the sequence context of the modification.

Ribosome profiling studies have reached slightly different conclusions regrding how modifications impact translation. These studies suggest that $\mathrm{m}^{1} \mathrm{~A}$ slows translation in mitochondria, and that $\mathrm{m}^{6} \mathrm{~A}$ and $\mathrm{ac}^{4} \mathrm{C}$ enhance translation efficiency (Arango et al., 2018; Li et al., 2017; Wang et al., 2015). There could be several reasons for the differing conclusions reached by ribosome profiling and in vitro studies including that modification reader proteins in the cell might alter translation, and, given the substoichiometric occurance of mRNA modifications, the possibility that the population of mRNAs being well translated might lack the targeted modification. Further work will need to be done to reconcile the relationship between the differing observations between in vitro and ribosome profiling studies.

Since modifications can alter the fundamental properties of RNAs, including their secondary structures and basepairing abilities, it has been proposed that one consequence of mRNA modification could be to promote the 
F I G U RE 6 Impact of messenger RNA (mRNA) modifications on mRNA-protein interactions and protein synthesis. (a) mRNAbinding protein affinities are modestly altered by nucleoside modifications. The ratio of binding affinities $\left(K_{\mathrm{D}}\right)$ for proteins binding to $\mathrm{m}^{6} \mathrm{~A}$ (gray bars) and $\Psi$ (black bars) unmodified and modified mRNA transcripts binding to a Pumilio proteins (PUM2), and the $\mathrm{m}^{6} \mathrm{~A}$ binding proteins proline-rich coiled-coil 2A (PRRC2A), YTHDF3, YTHDF2, YTHDC1, and insulin-like factor 2 mRNA binding proteins 1, 2, and 3 (IGF2BP1, IGF2BP2, IGF2BP3) (H. Huang et al., 2018; Vaidyanathan et al., 2017; X. Wang et al., 2014; R. Wu et al., 2019). The affinity of PUM2 was measured for model mRNAs containing 1 (PUM2_1) or 3 (PUM2_3) modifications. (b) Reporter proteins were expressed from mRNAs containing a single nucleotide modification in commercially available fully reconstituted bacterial translation assays. The plot displays the amount of protein produced from the modified mRNA relative to the amount of protein produced from an unmodified transcript as a function of codon. The values in this table were from studies by Hoernes, Clementi et al. (2016) and You et al. (2017). The magnitude of each modification's effect is depends not only on the identity of the modification, but also on the codon in which it is located, the position of the modification within that codon

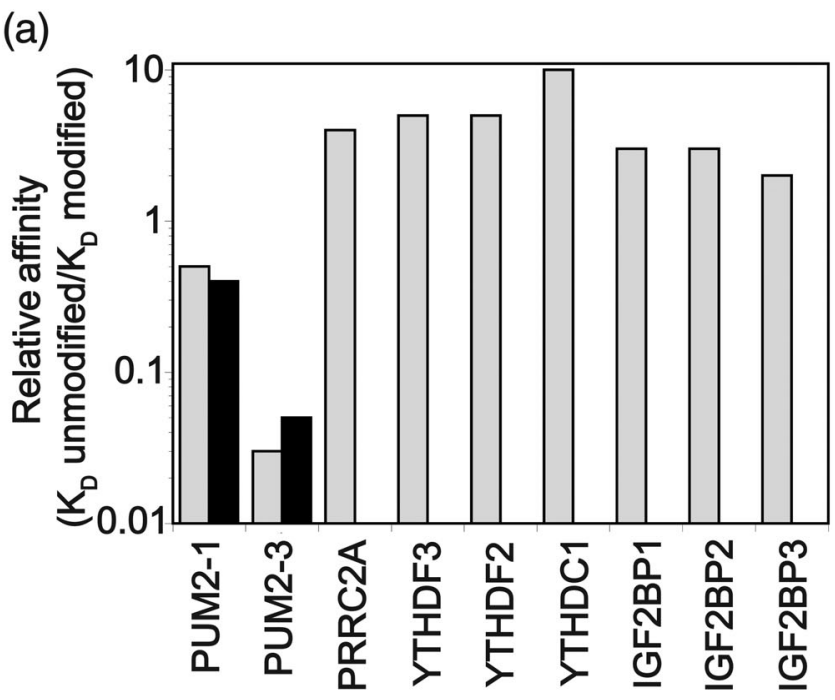

(b)

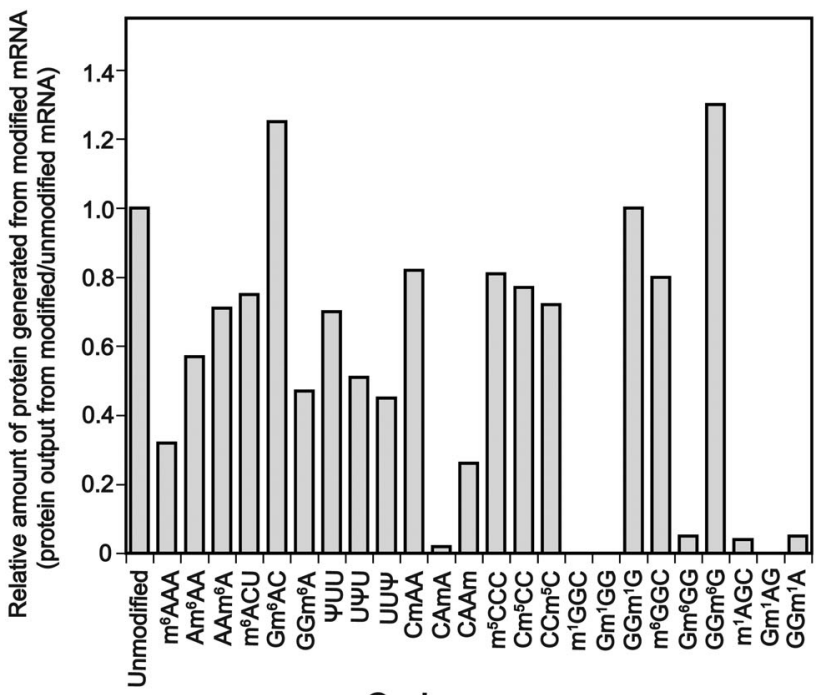

Codon

incorporation of multiple amino acids on a single codon. Establishing if modifications alter tRNA selection on the ribosome is a timely question given that a wide range of modified nucleosides ( $\Psi$, N1-methyl- $\Psi$, 2-thiouridine, 5-methylcytosine) are being routinely inserted into synthetic mRNAs at high stoichiometric ratios for therapeutic applications (Kariko et al., 2008). Multiple studies indicate that this is indeed possible for $\mathrm{m}^{5} \mathrm{C}, \mathrm{m}^{1} \mathrm{G}, \mathrm{I}, \Psi$, and $\mathrm{m}^{6} \mathrm{G}$, but not for $\mathrm{m}^{1} \mathrm{~A}$ and $\mathrm{m}^{6} \mathrm{~A}$ (Eyler et al., 2019; Garrett \& Rosenthal, 2012; Hoernes, Clementi, et al., 2016; Hudson \& Zaher, 2015; Licht et al., 2019). Similar to their effects on translation rate, the magnitude of the decoding errors is highly dependent on the position of a modified within a codon. Additionally, $\Psi$-containing stop codons have been observed to direct the nonsense suppression of translation termination in both bacteria and yeast (Fernandez et al., 2013; Hoernes et al., 2019; Hoernes, Clementi, et al., 2016; Karijolich \& Yu, 2011), though the impact of $\Psi$ in stop codons remains an unresolved question, as a follow-up studies have not recapitulated these effects (Eyler et al., 2019; Hoernes et al., 2019; Svidritskiy et al., 2016).

Taken together, there is a growing body of in vitro translation and ribosome profiling studies suggesting that mRNA modifications have the ability to influence both the rate and fidelity of translation. How these alterations contribute to biology still remains to be established. Even if mRNA modifications are not used to directly regulate translation, their impact on translation may still have consequences for biological systems, for example under stress conditions where increased levels of amino acid substitution have been shown to increase cellular fitness (Fan et al., 2017, 2015; M. H. Schwartz \& Pan, 2016). Further work will need to be done to determine the differential effects of individual 
modifications on the translation mechanism, and identify situations (e.g., times in the cell cycle, environmental stress, or disease) in which more somewhat subtle impacts on translation could contribute to cellular health.

\section{3 | mRNA-protein interactions modifications}

In addition to understanding how mRNA modifications impact translation, it is also important to gain quantitative insight into the extent that modifications affect mRNA-protein interactions. Modulation of mRNA-protein interactions has the potential to be biologically significant because many RNA binding proteins interact with a multiple mRNA sequences and even small perturbations in affinity have the potential to shift the cellular environment, and thus fate, of a host of mRNAs (Castello, Hentze, \& Preiss, 2015; Gerber, Herschlag, \& Brown, 2004; Hentze, Castello, Schwarzl, \& Preiss, 2018; Jarmoskaite et al., 2019; Lewis, Pan, \& Kalsotra, 2017; Patil et al., 2018; Singh, Pratt, Yeo, \& Moore, 2015; Ule et al., 2003; Vaidyanathan et al., 2017). Immunoprecipitation, pull-down, mass-spectrometry, and RNA-seq approaches have begun to identify proteins whose interactions with mRNAs are mediated by modifications. These studies reveal that $\mathrm{m}^{6} \mathrm{~A}, \mathrm{~m}^{1} \mathrm{~A}$, and $\mathrm{m}^{5} \mathrm{C}$ are specifically recognized by proteins that can either read or erase modifications to alter mRNA translation, localization, and stabilization (reviewed in X. Dai et al., 2018; X. Li et al., 2016; F. Liu et al., 2016; Peer et al., 2017; Roundtree, Evans, et al., 2017; S. Schwartz, 2016; Trixl \& Lusser, 2019; Yang et al., 2017). To date, no "readers" or "erasers" of other mRNA modifications have been reported, though it has been proposed that the ribosome can serve as a universal reader of modifications in mRNA coding regions (Gilbert, Bell, \& Schaening, 2016).

Modifications appear to modulate mRNA stability, suggesting that they impact, either directly or indirectly, interactions between mRNAs and the RNA degradation machinery. Notably, different modifications fine-tune stability in different directions $-\mathrm{m}^{6} \mathrm{~A}$ generally decreases stability, while $a c^{4} \mathrm{C}, \Psi$ and $\mathrm{m}^{5} \mathrm{C}$ tend to increase mRNA half-life (Arango et al., 2018; Kariko et al., 2008; Ke et al., 2017; Nakamoto et al., 2017; Sibbritt et al., 2013). It is not entirely clear precisely how this is accomplished, though the observation that the YTHDC $2 \mathrm{~m}^{6} \mathrm{~A}$ reader interacts with the major $5^{\prime} \rightarrow 3^{\prime}$ exonuclease involved in mRNA decay, Xrn1, suggests that interactions between modified mRNAs and components of the mRNA degradation pathway may, at least sometimes, be facilitated by modification binding proteins (Kretschmer et al., 2018).

Despite the discovery of several proteins that interact with modified mRNAs, the extent to which modifications alter mRNA-protein interactions is less clear. Thermodynamic dissociation constants $\left(K_{\mathrm{D}}\right)$ have only been measured for a handful of the proteins reported to bind modified mRNAs (examples in Figure 6). Initial studies of modified mRNAprotein interactions demonstrate that $\mathrm{m}^{6} \mathrm{~A}$ and $\Psi$ can both enhance and weaken RNA-protein interactions by $\sim 2$ - to 20 -fold (Figure 6). Members of the YTH-family of $\mathrm{m}^{6} \mathrm{~A}$ "reader" proteins appear to discriminate between methylated/ unmethylated transcripts to a higher level (5- to 20-fold) than other mRNA binding proteins (two- to four-fold) (Figure 6). Interestingly, these studies find modifications only induce relatively modest changes in protein affinities for mRNAs. This suggests that modifications could be more likely to subtly, rather than drastically, shift the balance, and identity of cellular mRNA-protein pools.

\section{4 | CONCLUSION}

The epitranscriptome field is quickly opening a new chapter, advancing through modification discovery to investigate the biological roles and mechanisms of a broad set of mRNA modifications. The ground-breaking investigations that established this burgeoning field of study relied heavily on sequencing-based tools to map the location of discrete modifications across all RNAs in a cell. Such studies were a vital first step for the field to establish the existence and pervasiveness of mRNA modifications. More recently, researchers have begun skillfully mining transcriptome wide datasets to infer the biological function of modifications. The next horizon for the emerging mRNA modification field is to establish a molecular-level view of how modifications change interactions between mRNAs and the cellular machinery.

A detailed understanding of the consequences of modifications will be greatly enhanced by the biochemical and structural characterization of individual cellular components and how they interact with modified mRNAs. The quantitative data generated from such experiments (e.g., affinities, on and off rates, reaction rates, etc.) will facilitate the interpretation of existing and future transcriptome wide studies, as they will provide parameters for the mRNA modification community to refine their models of modification function. Structural biology and reductionist biochemistry approaches will provide more than mechanistic details-they have the potential to generate new insights into the function of modifications that cannot be immediately derived by correlative studies. For example, these techniques can 
answer temporal questions, allow us to identify highly occupied modification sites, determine how specificity or promiscuity of modifying enzymes dictates target selection, and directly assess how modifications change interactions with the splicing, translation and decay machinery (Figure 3). The ability to compare interactions of fully modified/unmodified mRNAs with purified components will be particularly valuable in light of the challenges of interpreting transcriptome wide mapping, half-life, and ribosome profiling data for heterogenous populations of sub-stoichiometrically modified mRNAs. The initial quantitative studies described in this review demonstrate how biochemistry can reveal aspects of RNA-protein and mRNA-ribosome interactions that are masked by other approaches. The continued integration of quantitative, reductionist approaches combined and transcriptome wide studies will ultimately be required to identify the biological consequences of the epitranscriptome.

\section{CONFLICT OF INTEREST}

The authors have declared no conflicts of interest for this article.

\section{AUTHOR CONTRIBUTIONS}

Joshua Jones: Writing-original draft, review, and editing. Jeremy Monroe: Writing-original draft, review, and editing. Kristin Koutmou: Conceptualization; funding acquisition; writing-original draft, review, and editing.

\section{ORCID}

Kristin S. Koutmou (D) https://orcid.org/0000-0002-7763-9262

\section{RELATED WIRES ARTICLES}

Translating the epitranscriptome

\section{REFERENCES}

Alon, S., Garrett, S. C., Levanon, E. Y., Olson, S., Graveley, B. R., Rosenthal, J. J. C., \& Eisenberg, E. (2015). The majority of transcripts in the squid nervous system are extensively recoded by A-to-I RNA editing. eLife, 4, e05198. https://doi.org/10.7554/eLife.05198.001

Amort, T., Rieder, D., Wille, A., Khokhlova-Cubberley, D., Riml, C., Trixl, L., ... Lusser, A. (2017). Distinct 5-methylcytosine profiles in poly(A) RNA from mouse embryonic stem cells and brain. Genome Biology, 18(1), 1. https://doi.org/10.1186/s13059-016-1139-1

Angelova, M. T., Dimitrova, D. G., Dinges, N., Lence, T., Worpenberg, L., Carre, C., \& Roignant, J. Y. (2018). The emerging field of epitranscriptomics in neurodevelopmental and neuronal disorders. Frontiers in Bioengineering and Biotechnology, 6, 46. https://doi.org/10. 3389/fbioe.2018.00046

Anstee, Q. M., \& Day, C. P. (2012). S-adenosylmethionine (SAMe) therapy in liver disease: A review of current evidence and clinical utility. Journal of Hepatology, 57(5), 1097-1109. https://doi.org/10.1016/j.jhep.2012.04.041

Arango, D., Sturgill, D., Alhusaini, N., Dillman, A. A., Sweet, T. J., Hanson, G., ... Oberdoerffer, S. (2018). Acetylation of cytidine in mRNA promotes translation efficiency. Cell, 175(7), 1872-1886 e1824. https://doi.org/10.1016/j.cell.2018.10.030

Baeza, J., Dowell, J. A., Smallegan, M. J., Fan, J., Amador-Noguez, D., Khan, Z., \& Denu, J. M. (2014). Stoichiometry of site-specific lysine acetylation in an entire proteome. The Journal of Biological Chemistry, 289(31), 21326-21338. https://doi.org/10.1074/jbc.M114.581843

Bajad, P., Jantsch, M. F., Keegan, L., \& O'Connell, M. (2017). A to I editing in disease is not fake news. RNA Biology, 14(9), 1223-1231. https://doi.org/10.1080/15476286.2017.1306173

Baudin-Baillieu, A., Fabret, C., Liang, X. H., Piekna-Przybylska, D., Fournier, M. J., \& Rousset, J. P. (2009). Nucleotide modifications in three functionally important regions of the Saccharomyces cerevisiae ribosome affect translation accuracy. Nucleic Acids Research, 37(22), 7665-7677. https://doi.org/10.1093/nar/gkp816

Bazak, L., Haviv, A., Barak, M., Jacob-Hirsch, J., Deng, P., Zhang, R., ... Levanon, E. Y. (2014). A-to-I RNA editing occurs at over a hundred million genomic sites, located in a majority of human genes. Genome Research, 24(3), 365-376. https://doi.org/10.1101/gr.164749.113

Berman, H., Henrick, K., \& Nakamura, H. (2003). Announcing the worldwide protein data Bank. Nature Structural Biology, 10(12), 980. https://doi.org/10.1038/nsb1203-980

Carlile, T. M., Martinez, N. M., Schaening, C., Su, A., Bell, T. A., Zinshteyn, B., \& Gilbert, W. V. (2019). mRNA structure determines modification by pseudouridine synthase 1. Nature Chemical Biology, 15(10), 966-974. https://doi.org/10.1038/s41589-019-0353-Z

Carlile, T. M., Rojas-Duran, M. F., Zinshteyn, B., Shin, H., Bartoli, K. M., \& Gilbert, W. V. (2014). Pseudouridine profiling reveals regulated mRNA pseudouridylation in yeast and human cells. Nature, 515(7525), 143-146. https://doi.org/10.1038/nature13802

Carpy, A., Krug, K., Graf, S., Koch, A., Popic, S., Hauf, S., \& Macek, B. (2014). Absolute proteome and phosphoproteome dynamics during the cell cycle of schizosaccharomyces pombe (fission yeast). Molecular \& Cellular Proteomics, 13(8), 1925-1936. https://doi.org/10.1074/ mcp.M113.035824

Castello, A., Hentze, M. W., \& Preiss, T. (2015). Metabolic enzymes enjoying new partnerships as RNA-binding proteins. Trends in Endocrinology and Metabolism, 26(12), 746-757. https://doi.org/10.1016/j.tem.2015.09.012 
Chan, C. T., Dyavaiah, M., DeMott, M. S., Taghizadeh, K., Dedon, P. C., \& Begley, T. J. (2010). A quantitative systems approach reveals dynamic control of tRNA modifications during cellular stress. PLoS Genetics, 6(12), e1001247. https://doi.org/10.1371/journal.pgen. 1001247

Charette, M., \& Gray, M. W. (2000). Pseudouridine in RNA: What, where, how, and why. IUBMB Life, 49(5), 341-351. https://doi.org/10. 1080/152165400410182

Chen, K., Lu, Z., Wang, X., Fu, Y., Luo, G. Z., Liu, N., ... He, C. (2015). High-resolution N(6) -methyladenosine (m(6) A) map using photocrosslinking-assisted m(6) A sequencing. Angewandte Chemie (International Ed. in English), 54(5), 1587-1590. https://doi.org/10.1002/ anie. 201410647

Choi, J., Ieong, K. W., Demirci, H., Chen, J., Petrov, A., Prabhakar, A., ... Puglisi, J. D. (2016). N(6)-methyladenosine in mRNA disrupts tRNA selection and translation-elongation dynamics. Nature Structural \& Molecular Biology, 23(2), 110-115. https://doi.org/10.1038/nsmb.3148

Choi, J., Indrisiunaite, G., DeMirci, H., Ieong, K. W., Wang, J., Petrov, A., ... Puglisi, J. D. (2018). 2'-O-methylation in mRNA disrupts tRNA decoding during translation elongation. Nature Structural \& Molecular Biology, 25(3), 208-216. https://doi.org/10.1038/s41594-0180030-Z

Chu, J. M., Ye, T. T., Ma, C. J., Lan, M. D., Liu, T., Yuan, B. F., \& Feng, Y. Q. (2018). Existence of internal N7-methylguanosine modification in mRNA determined by differential enzyme treatment coupled with mass spectrometry analysis. ACS Chemical Biology, 13(12), 3243-3250. https://doi.org/10.1021/acschembio.7b00906

Cohn, W. E., \& Volkin, E. (1951). Nucleoside-5' -phosphates from ribonucleic acid. Nature, 167, 483-484.

Cross, R. (2019). Epitranscriptomics: The new RNA code and the race to drug it. Chemistry and Engineering News, 97(7).

Cui, Q., Shi, H., Ye, P., Li, L., Qu, Q., Sun, G., ... Shi, Y. (2017). m(6)A RNA methylation regulates the self-renewal and tumorigenesis of glioblastoma stem cells. Cell Reports, 18(11), 2622-2634. https://doi.org/10.1016/j.celrep.2017.02.059

Cui, X., Liang, Z., Shen, L., Zhang, Q., Bao, S., Geng, Y., ... Yu, H. (2017). 5-Methylcytosine RNA methylation in Arabidopsis thaliana. Molecular Plant, 10(11), 1387-1399. https://doi.org/10.1016/j.molp.2017.09.013

Dai, Q., Moshitch-Moshkovitz, S., Han, D., Kol, N., Amariglio, N., Rechavi, G., ... He, C. (2017). Nm-seq maps 2'-O-methylation sites in human mRNA with base precision. Nature Methods, 14(7), 695-698. https://doi.org/10.1038/nmeth.4294

Dai, X., Wang, T., Gonzalez, G., \& Wang, Y. (2018). Identification of YTH domain-containing proteins as the readers for N1-methyladenosine in RNA. Analytical Chemistry, 90(11), 6380-6384. https://doi.org/10.1021/acs.analchem.8b01703

Danecek, P., Nellaker, C., McIntyre, R. E., Buendia-Buendia, J. E., Bumpstead, S., Ponting, C. P., ... Adams, D. J. (2012). High levels of RNAediting site conservation amongst 15 laboratory mouse strains. Genome Biology, 13(4), 26. https://doi.org/10.1186/gb-2012-13-4-r26

Davis, D. R. (1995). Stabilization of RNA stacking by pseudouridine. Nucleic Acids Research, 23(24), 5020-5026. https://doi.org/10.1093/nar/ 23.24.5020

Davis, F. F., \& Worthington Allen, F. (1957). Ribonucleic acids from yeast which contain a fifth nucleotide. Journal of Biological Chemistry, 227, 907-915.

De Jesus, D. F., Zhang, Z., Kahraman, S., Brown, N. K., Chen, M., Hu, J., ... Kulkarni, R. N. (2019). m6A mRNA methylation regulates human $\beta$-cell biology in physiological states and in type 2 diabetes. Nature Metabolism, 1, 765-774. https://doi.org/10.1038/s42255-0190089-9

Delatte, B., Wang, F., Ngoc, L. V., Collignon, E., Bonvin, E., Deplus, R., ... Fuks, F. (2016). RNA biochemistry. Transcriptome wide distribution and function of RNA hydroxymethylcytosine. Science, 351(6270), 282-285. https://doi.org/10.1126/science.aac5253

Demirci, H., Murphy, F. t., Belardinelli, R., Kelley, A. C., Ramakrishnan, V., Gregory, S. T., ... Jogl, G. (2010). Modification of 16S ribosomal RNA by the KsgA methyltransferase restructures the 30S subunit to optimize ribosome function. RNA, 16(12), 2319-2324. https://doi. $\operatorname{org} / 10.1261 /$ rna.2357210

Deng, X., Chen, K., Luo, G. Z., Weng, X., Ji, Q., Zhou, T., \& He, C. (2015). Widespread occurrence of N6-methyladenosine in bacterial mRNA. Nucleic Acids Research, 43(13), 6557-6567. https://doi.org/10.1093/nar/gkv596

Desrosiers, R., Friderici, K., \& Rottman, F. (1974). Identification of methylated nucleosides in messenger RNA from Novikoff hepatoma cells. Proceedings of the National Academy of Sciences of the United States of America, 71(10), 3971-3975. https://doi.org/10.1073/pnas.71.10. 3971

Dominissini, D., Moshitch-Moshkovitz, S., Schwartz, S., Salmon-Divon, M., Ungar, L., Osenberg, S., ... Rechavi, G. (2012). Topology of the human and mouse m6A RNA methylomes revealed by m6A-seq. Nature, 485(7397), 201-206. https://doi.org/10.1038/nature11112

Dominissini, D., Nachtergaele, S., Moshitch-Moshkovitz, S., Peer, E., Kol, N., Ben-Haim, M. S., ... He, C. (2016). The dynamic N(1)methyladenosine methylome in eukaryotic messenger RNA. Nature, 530(7591), 441-446. https://doi.org/10.1038/nature16998

Duan, H. C., Wei, L. H., Zhang, C., Wang, Y., Chen, L., Lu, Z., ... Jia, G. (2017). ALKBH10B is an RNA N(6)-methyladenosine demethylase affecting arabidopsis floral transition. Plant Cell, 29(12), 2995-3011. https://doi.org/10.1105/tpc.16.00912

Edupuganti, R. R., Geiger, S., Lindeboom, R. G. H., Shi, H., Hsu, P. J., Lu, Z., ... Vermeulen, M. (2017). N(6)-methyladenosine (m(6)A) recruits and repels proteins to regulate mRNA homeostasis. Nature Structural \& Molecular Biology, 24(10), 870-878. https://doi.org/10. 1038/nsmb.3462

Eyler, D. E., Franco, M. K., Batool, Z., Wu, M. Z., Debuke, M. L., Dobosz-Bartoszek, M., ... Koutmou, K. S. (2019). Pseudouridinylation of mRNA coding sequences alters translation. Proceedings of the National Academy of Sciences of the United States of America, 116(46), 23068-23074. https://doi.org/10.1073/pnas.1821754116 
Fan, Y., Evans, C. R., Barber, K. W., Banerjee, K., Weiss, K. J., Margolin, W., ... Ling, J. (2017). Heterogeneity of stop codon readthrough in single bacterial cells and implications for population fitness. Molecular Cell, 67(5), 826-836 e825. https://doi.org/10.1016/j.molcel.2017. 07.010

Fan, Y., Wu, J., Ung, M. H., De Lay, N., Cheng, C., \& Ling, J. (2015). Protein mistranslation protects bacteria against oxidative stress. Nucleic Acids Research, 43(3), 1740-1748. https://doi.org/10.1093/nar/gku1404

Fernandez, I. S., Ng, C. L., Kelley, A. C., Wu, G., Yu, Y. T., \& Ramakrishnan, V. (2013). Unusual base pairing during the decoding of a stop codon by the ribosome. Nature, 500(7460), 107-110. https://doi.org/10.1038/nature12302

Ferreira, P. G., Oti, M., Barann, M., Wieland, T., Ezquina, S., Friedlander, M. R., ... Sammeth, M. (2016). Sequence variation between 462 human individuals fine-tunes functional sites of RNA processing. Scientific Reports, 6, 32406. https://doi.org/10.1038/srep32406

Frye, M., Harada, B. T., Behm, M., \& He, C. (2018). RNA modifications modulate gene expression during development. Science, 361(6409), 1346-1349. https://doi.org/10.1126/science.aau1646

Fustin, J. M., Kojima, R., Itoh, K., Chang, H. Y., Ye, S., Zhuang, B., ... Okamura, H. (2018). Two Ck1delta transcripts regulated by m6A methylation code for two antagonistic kinases in the control of the circadian clock. Proceedings of the National Academy of Sciences of the United States of America, 115(23), 5980-5985. https://doi.org/10.1073/pnas.1721371115

Garcia-Campos, M. A., Edelheit, S., Toth, U., Safra, M., Shachar, R., Viukov, S., ... Schwartz, S. (2019). Deciphering the "m(6)A code" via antibody-independent quantitative profiling. Cell, 178(3), 731-747 e716. https://doi.org/10.1016/j.cell.2019.06.013

Garrett, S., \& Rosenthal, J. J. (2012). RNA editing underlies temperature adaptation in K+ channels from polar octopuses. Science, 335(6070), 848-851. https://doi.org/10.1126/science.1212795

Gerber, A. P., Herschlag, D., \& Brown, P. O. (2004). Extensive association of functionally and cytotopically related mRNAs with Puf family RNA-binding proteins in yeast. PLoS Biology, 2(3), E79. https://doi.org/10.1371/journal.pbio.0020079

Gilbert, W. V., Bell, T. A., \& Schaening, C. (2016). Messenger RNA modifications: Form, distribution, and function. Science, 352(6292), 1408-1412. https://doi.org/10.1126/science.aad8711

Grozhik, A. V., \& Jaffrey, S. R. (2018). Distinguishing RNA modifications from noise in epitranscriptome maps. Nature Chemical Biology, 14 (3), 215-225. https://doi.org/10.1038/nchembio.2546

Hansen, B. K., Gupta, R., Baldus, L., Lyon, D., Narita, T., Lammers, M., ... Weinert, B. T. (2019). Analysis of human acetylation stoichiometry defines mechanistic constraints on protein regulation. Nature Communications, 10(1), 1055. https://doi.org/10.1038/s41467-019-09024-0

Haussmann, I. U., Bodi, Z., Sanchez-Moran, E., Mongan, N. P., Archer, N., Fray, R. G., \& Soller, M. (2016). m(6)A potentiates Sxl alternative pre-mRNA splicing for robust Drosophila sex determination. Nature, 540(7632), 301-304. https://doi.org/10.1038/nature20577

Helm, M., \& Alfonzo, J. D. (2017). Posttranscriptional RNA modifications: Playing metabolic games in a cell's chemical Legoland. Chemical Biology, 21(2), 174-185.

Helm, M., \& Motorin, Y. (2017). Detecting RNA modifications in the epitranscriptome: Predict and validate. Nature Reviews. Genetics, 18(5), 275-291. https://doi.org/10.1038/nrg.2016.169

Hentze, M. W., Castello, A., Schwarzl, T., \& Preiss, T. (2018). A brave new world of RNA-binding proteins. Nature Reviews. Molecular Cell Biology, 19(5), 327-341. https://doi.org/10.1038/nrm.2017.130

Hoernes, T. P., Clementi, N., Faserl, K., Glasner, H., Breuker, K., Lindner, H., ... Erlacher, M. D. (2016). Nucleotide modifications within bacterial messenger RNAs regulate their translation and are able to rewire the genetic code. Nucleic Acids Research, 44(2), 852-862. https:// doi.org/10.1093/nar/gkv1182

Hoernes, T. P., Clementi, N., Juen, M. A., Shi, X., Faserl, K., Willi, J., ... Erlacher, M. D. (2018). Atomic mutagenesis of stop codon nucleotides reveals the chemical prerequisites for release factor-mediated peptide release. Proceedings of the National Academy of Sciences of the United States of America, 115(3), E382-E389. https://doi.org/10.1073/pnas.1714554115

Hoernes, T. P., Heimdorfer, D., Kostner, D., Faserl, K., Nussbaumer, F., Plangger, R., ... Erlacher, M. D. (2019). Eukaryotic translation elongation is modulated by single natural nucleotide derivatives in the coding sequences of mRNAs. Genes (Basel), 10(2). https://doi.org/10. 3390/genes10020084

Hoernes, T. P., Huttenhofer, A., \& Erlacher, M. D. (2016). mRNA modifications: Dynamic regulators of gene expression? RNA Biology, 13(9), 760-765. https://doi.org/10.1080/15476286.2016.1203504

Huang, H., Weng, H., Sun, W., Qin, X., Shi, H., Wu, H., ... Chen, J. (2018). Recognition of RNA N(6)-methyladenosine by IGF2BP proteins enhances mRNA stability and translation. Nature Cell Biology, 20(3), 285-295. https://doi.org/10.1038/s41556-018-0045-Z

Huang, T., Chen, W., Liu, J., Gu, N., \& Zhang, R. (2019). Genome-wide identification of mRNA 5-methylcytosine in mammals. Nature Structural \& Molecular Biology, 26(5), 380-388. https://doi.org/10.1038/s41594-019-0218-x

Huber, S. M., van Delft, P., Mendil, L., Bachman, M., Smollett, K., Werner, F., ... Balasubramanian, S. (2015). Formation and abundance of 5-hydroxymethylcytosine in RNA. Chembiochem, 16(5), 752-755. https://doi.org/10.1002/cbic.201500013

Hudson, B. H., \& Zaher, H. S. (2015). O6-Methylguanosine leads to position-dependent effects on ribosome speed and fidelity. RNA, 21(9), 1648-1659. https://doi.org/10.1261/rna.052464.115

Ingolia, N. T., Ghaemmaghami, S., Newman, J. R., \& Weissman, J. S. (2009). Genome-wide analysis in vivo of translation with nucleotide resolution using ribosome profiling. Science, 324(5924), 218-223. https://doi.org/10.1126/science.1168978

Jain, M., Olsen, H. E., Paten, B., \& Akeson, M. (2016). The Oxford nanopore MinION: Delivery of nanopore sequencing to the genomics community. Genome Biology, 17(1), 239. https://doi.org/10.1186/s13059-016-1103-0 
Jarmoskaite, I., Denny, S. K., Vaidyanathan, P. P., Becker, W. R., Andreasson, J. O. L., Layton, C. J., ... Herschlag, D. (2019). A quantitative and predictive model for RNA binding by human Pumilio proteins. Molecular Cell, 74(5), 966-981 e918. https://doi.org/10.1016/j.molcel. 2019.04.012

Jia, G., Fu, Y., Zhao, X., Dai, Q., Zheng, G., Yang, Y., ... He, C. (2011). N6-methyladenosine in nuclear RNA is a major substrate of the obesity-associated FTO. Nature Chemical Biology, 7(12), 885-887. https://doi.org/10.1038/nchembio.687

Karijolich, J., \& Yu, Y. T. (2011). Converting nonsense codons into sense codons by targeted pseudouridylation. Nature, 474(7351), 395-398. https://doi.org/10.1038/nature10165

Kariko, K., Muramatsu, H., Welsh, F. A., Ludwig, J., Kato, H., Akira, S., \& Weissman, D. (2008). Incorporation of pseudouridine into mRNA yields superior nonimmunogenic vector with increased translational capacity and biological stability. Molecular Therapy, 16(11), 1833-1840. https://doi.org/10.1038/mt.2008.200

Ke, S., Pandya-Jones, A., Saito, Y., Fak, J. J., Vagbo, C. B., Geula, S., ... Darnell, R. B. (2017). m(6)A mRNA modifications are deposited in nascent pre-mRNA and are not required for splicing but do specify cytoplasmic turnover. Genes \& Development, 31(10), 990-1006. https://doi.org/10.1101/gad.301036.117

Kennedy, E. M., Courtney, D. G., Tsai, K., \& Cullen, B. R. (2017). Viral Epitranscriptomics. Journal of Virology, 91(9), e02263-16. https://doi. org/10.1128/JVI.02263-16

Khoddami, V., Yerra, A., Mosbruger, T. L., Fleming, A. M., Burrows, C. J., \& Cairns, B. R. (2019). Transcriptome wide profiling of multiple RNA modifications simultaneously at single-base resolution. Proceedings of the National Academy of Sciences of the United States of America, 116(14), 6784-6789. https://doi.org/10.1073/pnas.1817334116

Kim, D. D., Kim, T. T., Walsh, T., Kobayashi, Y., Matise, T. C., Buyske, S., \& Gabriel, A. (2004). Widespread RNA editing of embedded alu elements in the human transcriptome. Genome Research, 14(9), 1719-1725. https://doi.org/10.1101/gr.2855504

Kowalak, J. A., Pomerantz, S. C., Crain, P. F., \& McCloskey, J. A. (1993). A novel method for the determination of post-transcriptional modification in RNA by mass spectrometry. Nucleic Acids Research, 21(19), 4577-4585. https://doi.org/10.1093/nar/21.19.4577

Kretschmer, J., Rao, H., Hackert, P., Sloan, K. E., Hobartner, C., \& Bohnsack, M. T. (2018). The m(6)A reader protein YTHDC2 interacts with the small ribosomal subunit and the $5^{\prime}-3^{\prime}$ exoribonuclease XRN1. RNA, 24(10), 1339-1350. https://doi.org/10.1261/rna.064238.117

Lareau, L. F., Hite, D. H., Hogan, G. J., \& Brown, P. O. (2014). Distinct stages of the translation elongation cycle revealed by sequencing ribosome-protected mRNA fragments. eLife, 3, e01257. https://doi.org/10.7554/eLife.01257

Levanon, E. Y., Eisenberg, E., Yelin, R., Nemzer, S., Hallegger, M., Shemesh, R., ... Jantsch, M. F. (2004). Systematic identification of abundant A-to-I editing sites in the human transcriptome. Nature Biotechnology, 22, 1001-1005.

Lewis, C. J., Pan, T., \& Kalsotra, A. (2017). RNA modifications and structures cooperate to guide RNA-protein interactions. Nature Reviews. Molecular Cell Biology, 18(3), 202-210. https://doi.org/10.1038/nrm.2016.163

Li, L. J., Fan, Y. G., Leng, R. X., Pan, H. F., \& Ye, D. Q. (2018). Potential link between m(6)A modification and systemic lupus erythematosus. Molecular Immunology, 93, 55-63. https://doi.org/10.1016/j.molimm.2017.11.009

Li, X., Xiong, X., Wang, K., Wang, L., Shu, X., Ma, S., \& Yi, C. (2016). Transcriptome wide mapping reveals reversible and dynamic N(1)methyladenosine methylome. Nature Chemical Biology, 12(5), 311-316. https://doi.org/10.1038/nchembio.2040

Li, X., Xiong, X., Zhang, M., Wang, K., Chen, Y., Zhou, J., ... Yi, C. (2017). Base-resolution mapping reveals distinct m(1)A methylome in nuclear- and mitochondrial-encoded transcripts. Molecular Cell, 68(5), 993-1005 e1009. https://doi.org/10.1016/j.molcel.2017.10.019

Li, X., Zhu, P., Ma, S., Song, J., Bai, J., Sun, F., \& Yi, C. (2015). Chemical pulldown reveals dynamic pseudouridylation of the mammalian transcriptome. Nature Chemical Biology, 11(8), 592-597. https://doi.org/10.1038/nchembio.1836

Licht, K., Hartl, M., Amman, F., Anrather, D., Janisiw, M. P., \& Jantsch, M. F. (2019). Inosine induces context-dependent recoding and translational stalling. Nucleic Acids Research, 47(1), 3-14. https://doi.org/10.1093/nar/gky1163

Lin, S., Choe, J., Du, P., Triboulet, R., \& Gregory, R. I. (2016). The m(6)A methyltransferase METTL3 promotes translation in human cancer cells. Molecular Cell, 62(3), 335-345. https://doi.org/10.1016/j.molcel.2016.03.021

Linder, B., Grozhik, A. V., Olarerin-George, A. O., Meydan, C., Mason, C. E., \& Jaffrey, S. R. (2015). Single-nucleotide-resolution mapping of m6A and m6Am throughout the transcriptome. Nature Methods, 12(8), 767-772. https://doi.org/10.1038/nmeth.3453

Liu, B., Merriman, D. K., Choi, S. H., Schumacher, M. A., Plangger, R., Kreutz, C., ... Al-Hashimi, H. M. (2018). A potentially abundant junctional RNA motif stabilized by m(6)A and Mg(2). Nature Communications, 9(1), 2761. https://doi.org/10.1038/s41467-018-05243-Z

Liu, F., Clark, W., Luo, G., Wang, X., Fu, Y., Wei, J., ... He, C. (2016). ALKBH1-mediated tRNA demethylation regulates translation. Cell, 167 (3), 816-828 e816. https://doi.org/10.1016/j.cell.2016.09.038

Liu, N., Parisien, M., Dai, Q., Zheng, G., He, C., \& Pan, T. (2013). Probing N6-methyladenosine RNA modification status at single nucleotide resolution in mRNA and long noncoding RNA. RNA, 19(12), 1848-1856. https://doi.org/10.1261/rna.041178.113

Lovejoy, A. F., Riordan, D. P., \& Brown, P. O. (2014). Transcriptome wide mapping of pseudouridines: Pseudouridine synthases modify specific mRNAs in S. cerevisiae. PLoS One, 9(10), e110799. https://doi.org/10.1371/journal.pone.0110799

Lugowski, A., Nicholson, B., \& Rissland, O. S. (2018). Determining mRNA half-lives on a transcriptome wide scale. Methods, 137, 90-98. https://doi.org/10.1016/j.ymeth.2017.12.006

Ma, C. J., Ding, J. H., Ye, T. T., Yuan, B. F., \& Feng, Y. Q. (2019). AlkB homologue 1 demethylates N(3)-methylcytidine in mRNA of mammals. ACS Chemical Biology, 14(7), 1418-1425. https://doi.org/10.1021/acschembio.8b01001

Maraia, R. J., \& Arimbasseri, A. G. (2017). Factors that shape eukaryotic tRNAomes: Processing, modification and anticodon-codon use. Biomolecules, 7(1), E26. https://doi.org/10.3390/biom7010026 
Martinez-Perez, M., Aparicio, F., Lopez-Gresa, M. P., Belles, J. M., Sanchez-Navarro, J. A., \& Pallas, V. (2017). Arabidopsis m(6)A demethylase activity modulates viral infection of a plant virus and the m(6)A abundance in its genomic RNAs. Proceedings of the National Academy of Sciences of the United States of America, 114(40), 10755-10760. https://doi.org/10.1073/pnas.1703139114

Mauger, D. M., Cabral, B. J., Presnyak, V., Su, S. V., Reid, D. W., Goodman, B., ... McFadyen, I. J. (2019). mRNA structure regulates protein expression through changes in functional half-life. Proceedings of the National Academy of Sciences of the United States of America, 116 (48), 24075-24083. https://doi.org/10.1073/pnas.1908052116

Meyer, K. D., Saletore, Y., Zumbo, P., Elemento, O., Mason, C. E., \& Jaffrey, S. R. (2012). Comprehensive analysis of mRNA methylation reveals enrichment in 3' UTRs and near stop codons. Cell, 149(7), 1635-1646. https://doi.org/10.1016/j.cell.2012.05.003

Molinie, B., Wang, J., Lim, K. S., Hillebrand, R., Lu, Z. X., Van Wittenberghe, N., ... Giallourakis, C. C. (2016). m(6)A-LAIC-seq reveals the census and complexity of the m(6)A epitranscriptome. Nature Methods, 13(8), 692-698. https://doi.org/10.1038/nmeth.3898

Morse, D. P., \& Bass, B. L. (1997). Detection of inosine in messenger RNA by inosine-specific cleavage. Biochemistry, 36(28), 8429-8434. https://doi.org/10.1021/bi9709607

Motorin, Y., \& Helm, M. (2019). Methods for RNA modification mapping using deep sequencing: Established and new emerging technologies. Genes (Basel), 10(1), E35. https://doi.org/10.3390/genes10010035

Nachtergaele, S., \& He, C. (2017). The emerging biology of RNA post-transcriptional modifications. RNA Biology, 14(2), 156-163. https://doi. $\operatorname{org} / 10.1080 / 15476286.2016 .1267096$

Nakamoto, M. A., Lovejoy, A. F., Cygan, A. M., \& Boothroyd, J. C. (2017). mRNA pseudouridylation affects RNA metabolism in the parasite Toxoplasma gondii. RNA, 23(12), 1834-1849. https://doi.org/10.1261/rna.062794.117

Nishikura, K. (2016). A-to-I editing of coding and non-coding RNAs by ADARs. Nature Reviews. Molecular Cell Biology, 17(2), 83-96. https:// doi.org/10.1038/nrm.2015.4

Olsen, J. V., Vermeulen, M., Santamaria, A., Kumar, C., Miller, M. L., Jensen, L. J., ... Mann, M. (2010). Quantitative phosphoproteomics reveals widespread full phosphorylation site occupancy during mitosis. Science Signaling, 3(104), ra3. https://doi.org/10.1126/scisignal. 2000475

Pan, T. (2018). Modifications and functional genomics of human transfer RNA. Cell Research, 28(4), 395-404. https://doi.org/10.1038/s41422018-0013-y

Pandey, R. R., \& Pillai, R. S. (2019). Counting the cuts: MAZTER-Seq quantifies m(6)A levels using a methylation-sensitive ribonuclease. Cell, 178(3), 515-517. https://doi.org/10.1016/j.cell.2019.07.006

Patil, D. P., Pickering, B. F., \& Jaffrey, S. R. (2018). Reading m(6)A in the transcriptome: m(6)A-binding proteins. Trends in Cell Biology, 28 (2), 113-127. https://doi.org/10.1016/j.tcb.2017.10.001

Paul, M. S. (1998). Inosine exists in mRNA at tissue-specific levels and is most abundant in brain mRNA. The EMBO Journal, 17(4), 1120-1127. https://doi.org/10.1093/emboj/17.4.1120

Peer, E., Rechavi, G., \& Dominissini, D. (2017). Epitranscriptomics: Regulation of mRNA metabolism through modifications. Current Opinion in Chemical Biology, 41, 93-98. https://doi.org/10.1016/j.cbpa.2017.10.008

Pendleton, K. E., Chen, B., Liu, K., Hunter, O. V., Xie, Y., Tu, B. P., \& Conrad, N. K. (2017). The U6 snRNA m(6)A methyltransferase METTL16 regulates SAM synthetase intron retention. Cell, 169(5), 824-835 e814. https://doi.org/10.1016/j.cell.2017.05.003

Peng, X., Xu, X., Wang, Y., Hawke, D. H., Yu, S., Han, L., ... Mills, G. B. (2018). A-to-I RNA editing contributes to proteomic diversity in cancer. Cancer Cell, 33(5), 817-828 e817. https://doi.org/10.1016/j.ccell.2018.03.026

Perry, R. P., \& Kelley, D. E. (1974). Existence of methylated messenger RNA in mouse L cells. Cell, 1(1), 37-42. https://doi.org/10.1016/00928674(74)90153-6

Perry, R. P., Kelley, D. E., Friderici, K., \& Rottman, F. (1975). The methylated constituents of L cell messenger RNA: Evidence for an unusual cluster at the $5^{\prime}$ terminus. Cell, 4(4), 387-394. https://doi.org/10.1016/0092-8674(75)90159-2

Phizicky, E. M., \& Hopper, A. K. (2015). tRNA processing, modification, and subcellular dynamics: Past, present, and future. RNA, 21(4), 483-485. https://doi.org/10.1261/rna.049932.115

Pietrocola, F., Galluzzi, L., Bravo-San Pedro, J. M., Madeo, F., \& Kroemer, G. (2015). Acetyl coenzyme A: A central metabolite and second messenger. Cell Metabolism, 21(6), 805-821. https://doi.org/10.1016/j.cmet.2015.05.014

Pomerantz, S. C., \& Mccloskey, J. A. (1990). Analysis of RNA hydrolyzates by liquid-chromatography mass-spectrometry. Methods in Enzymology, 193, 796-824. https://doi.org/10.1016/0076-6879(90)93452-Q

Presnyak, V., Alhusaini, N., Chen, Y. H., Martin, S., Morris, N., Kline, N., ... Coller, J. (2015). Codon optimality is a major determinant of mRNA stability. Cell, 160(6), 1111-1124. https://doi.org/10.1016/j.cell.2015.02.029

Prus, G., Hoegl, A., Weinert, B. T., \& Choudhary, C. (2019). Analysis and interpretation of protein post-translational modification site stoichiometry. Trends in Biochemical Sciences, 44(11), 943-960. https://doi.org/10.1016/j.tibs.2019.06.003

Radhakrishnan, A., Chen, Y. H., Martin, S., Alhusaini, N., Green, R., \& Coller, J. (2016). The DEAD-box protein Dhh1p couples mRNA decay and translation by monitoring codon optimality. Cell, 167(1), 122-132 e129. https://doi.org/10.1016/j.cell.2016.08.053

Rajecka, V., Skalicky, T., \& Vanacova, S. (2019). The role of RNA adenosine demethylases in the control of gene expression. Biochimica et Biophysica Acta - Gene Regulatory Mechanisms, 1862(3), 343-355. https://doi.org/10.1016/j.bbagrm.2018.12.001

Ramaswami, G., Zhang, R., Piskol, R., Keegan, L. P., Deng, P., O'Connell, M. A., \& Li, J. B. (2013). Identifying RNA editing sites using RNA sequencing data alone. Nature Methods, 10(2), 128-132. https://doi.org/10.1038/nmeth.2330

Ranjan, N., \& Rodnina, M. V. (2017). Thio-modification of tRNA at the wobble position as regulator of the kinetics of decoding and translocation on the ribosome. Journal of the American Chemical Society, 139(16), 5857-5864. https://doi.org/10.1021/jacs.7b00727 
Roost, C., Lynch, S. R., Batista, P. J., Qu, K., Chang, H. Y., \& Kool, E. T. (2015). Structure and thermodynamics of N6-methyladenosine in RNA: A spring-loaded base modification. Journal of the American Chemical Society, 137(5), 2107-2115. https://doi.org/10.1021/ja513080v

Rottman, F., Shatkin, A. J., \& Perry, R. P. (1974). Sequences containing methylated nucleotides at the 5' termini of messenger RNAs: Possible implications for processing. Cell, 3(3), 197-199. https://doi.org/10.1016/0092-8674(74)90131-7

Roundtree, I. A., Evans, M. E., Pan, T., \& He, C. (2017). Dynamic RNA modifications in gene expression regulation. Cell, 169(7), 1187-1200. https://doi.org/10.1016/j.cell.2017.05.045

Roundtree, I. A., Luo, G. Z., Zhang, Z., Wang, X., Zhou, T., Cui, Y., ... He, C. (2017). YTHDC1 mediates nuclear export of N(6)methyladenosine methylated mRNAs. eLife, 6, e31311. https://doi.org/10.7554/eLife.31311

Rueter, S. M., Dawson, T. R., \& Emeson, R. B. (1999). Regulation of alternative splicing by RNA editing. Nature, 399(6731), 75-80. https:// doi.org/10.1038/19992

Russell, S. P., \& Limbach, P. A. (2013). Evaluating the reproducibility of quantifying modified nucleosides from ribonucleic acids by LC-UVMS. Journal of Chromatography. B, Analytical Technologies in the Biomedical and Life Sciences, 923-924, 74-82. https://doi.org/10.1016/j. jchromb.2013.02.010

Safra, M., Sas-Chen, A., Nir, R., Winkler, R., Nachshon, A., Bar-Yaacov, D., ... Schwartz, S. (2017). The m1A landscape on cytosolic and mitochondrial mRNA at single-base resolution. Nature, 551(7679), 251-255. https://doi.org/10.1038/nature24456

Sakurai, M., Ueda, H., Yano, T., Okada, S., Terajima, H., Mitsuyama, T., ... Suzuki, T. (2014). A biochemical landscape of A-to-I RNA editing in the human brain transcriptome. Genome Research, 24(3), 522-534. https://doi.org/10.1101/gr.162537.113

Sakurai, M., Yano, T., Kawabata, H., Ueda, H., \& Suzuki, T. (2010). Inosine cyanoethylation identifies A-to-I RNA editing sites in the human transcriptome. Nature Chemical Biology, 6(10), 733-740. https://doi.org/10.1038/nchembio.434

Saletore, Y., Meyer, K., Korlach, J., Vilfan, I. D., Jaffrey, S., \& Mason, C. E. (2012). The birth of the epitranscriptome: Deciphering the function of RNA modifications. Genome Biology, 13(10), 175. https://doi.org/10.1186/gb-2012-13-10-175

Schwartz, M. H., \& Pan, T. (2016). Temperature dependent mistranslation in a hyperthermophile adapts proteins to lower temperatures. Nucleic Acids Research, 44(1), 294-303. https://doi.org/10.1093/nar/gkv1379

Schwartz, S. (2016). Cracking the epitranscriptome. RNA, 22(2), 169-174. https://doi.org/10.1261/rna.054502.115

Schwartz, S., Bernstein, D. A., Mumbach, M. R., Jovanovic, M., Herbst, R. H., Leon-Ricardo, B. X., ... Regev, A. (2014). Transcriptome wide mapping reveals widespread dynamic-regulated pseudouridylation of ncRNA and mRNA. Cell, 159(1), 148-162. https://doi.org/10.1016/ j.cell.2014.08.028

Sendinc, E., Valle-Garcia, D., Dhall, A., Chen, H., Henriques, T., Navarrete-Perea, J., ... Shi, Y. (2019). PCIF1 catalyzes m6Am mRNA methylation to regulate gene expression. Molecular Cell, 75(3), 620-630 e629. https://doi.org/10.1016/j.molcel.2019.05.030

Sergiev, P. V., Aleksashin, N. A., Chugunova, A. A., Polikanov, Y. S., \& Dontsova, O. A. (2018). Structural and evolutionary insights into ribosomal RNA methylation. Nature Chemical Biology, 14(3), 226-235. https://doi.org/10.1038/nchembio.2569

Shi, H., Wei, J., \& He, C. (2019). Where, when, and how: Context-dependent functions of RNA methylation writers, readers, and erasers. Molecular Cell, 74(4), 640-650. https://doi.org/10.1016/j.molcel.2019.04.025

Shi, L., \& Tu, B. P. (2015). Acetyl-CoA and the regulation of metabolism: Mechanisms and consequences. Current Opinion in Cell Biology, 33, 125-131. https://doi.org/10.1016/j.ceb.2015.02.003

Sibbritt, T., Patel, H. R., \& Preiss, T. (2013). Mapping and significance of the mRNA methylome. WIREs RNA, 4(4), 397-422. https://doi.org/ 10.1002/wrna.1166

Singh, G., Pratt, G., Yeo, G. W., \& Moore, M. J. (2015). The clothes make the mRNA: Past and present trends in mRNP fashion. Annual Review of Biochemistry, 84, 325-354. https://doi.org/10.1146/annurev-biochem-080111-092106

Spitale, R. C., Flynn, R. A., Zhang, Q. C., Crisalli, P., Lee, B., Jung, J. W., ... Chang, H. Y. (2015). Structural imprints in vivo decode RNA regulatory mechanisms. Nature, 519(7544), 486-490. https://doi.org/10.1038/nature14263

Squires, J. E., Patel, H. R., Nousch, M., Sibbritt, T., Humphreys, D. T., Parker, B. J., ... Preiss, T. (2012). Widespread occurrence of 5-methylcytosine in human coding and non-coding RNA. Nucleic Acids Research, 40(11), 5023-5033. https://doi.org/10.1093/nar/gks144

Su, D., Chan, C. T., Gu, C., Lim, K. S., Chionh, Y. H., McBee, M. E., ... Dedon, P. C. (2014). Quantitative analysis of ribonucleoside modifications in tRNA by HPLC-coupled mass spectrometry. Nature Protocols, 9(4), 828-841. https://doi.org/10.1038/nprot.2014.047

Sun, H., Zhang, M., Li, K., Bai, D., \& Yi, C. (2019). Cap-specific, terminal N(6)-methylation by a mammalian m(6)Am methyltransferase. Cell Research, 29(1), 80-82. https://doi.org/10.1038/s41422-018-0117-4

Sun, L., Xu, Y., Bai, S., Bai, X., Zhu, H., Dong, H., ... Song, C. P. (2019). Transcriptome wide analysis of pseudouridylation of mRNA and non-coding RNAs in arabidopsis. Journal of Experimental Botany, 70(19), 5089-5600. https://doi.org/10.1093/jxb/erz273

Sun, S., \& Zhang, H. (2015). Large-scale measurement of absolute protein glycosylation stoichiometry. Analytical Chemistry, 87(13), 6479-6482. https://doi.org/10.1021/acs.analchem.5b01679

Svidritskiy, E., Madireddy, R., \& Korostelev, A. A. (2016). Structural basis for translation termination on a pseudouridylated stop codon. Journal of Molecular Biology, 428(10 Pt B), 2228-2236. https://doi.org/10.1016/j.jmb.2016.04.018

Tardu, M., Jones, J. D., Kennedy, R. T., Lin, Q., \& Koutmou, K. S. (2019). Identification and quantification of modified nucleosides in Saccharomyces cerevisiae mRNAs. ACS Chemical Biology, 14(7), 1403-1409. https://doi.org/10.1021/acschembio.9b00369

Trixl, L., \& Lusser, A. (2019). The dynamic RNA modification 5-methylcytosine and its emerging role as an epitranscriptomic mark. WIREs RNA, 10(1), e1510. https://doi.org/10.1002/wrna.1510 
Tsai, C. F., Wang, Y. T., Yen, H. Y., Tsou, C. C., Ku, W. C., Lin, P. Y., ... Chen, Y. J. (2015). Large-scale determination of absolute phosphorylation stoichiometries in human cells by motif-targeting quantitative proteomics. Nature Communications, 6, 6622. https://doi.org/10. 1038/ncomms7622

Ule, J., Jensen, K. B., Ruggiu, M., Mele, A., Ule, A., \& Darnell, R. B. (2003). CLIP identifies Nova-regulated RNA networks in the brain. Science, 302(5648), 1212-1215. https://doi.org/10.1126/science.1090095

Vaidyanathan, P. P., AlSadhan, I., Merriman, D. K., Al-Hashimi, H. M., \& Herschlag, D. (2017). Pseudouridine and N(6)-methyladenosine modifications weaken PUF protein/RNA interactions. RNA, 23(5), 611-618. https://doi.org/10.1261/rna.060053.116

Walkley, C. R., \& Li, J. B. (2017). Rewriting the transcriptome: Adenosine-to-inosine RNA editing by ADARs. Genome Biology, $18(1), 205$. https://doi.org/10.1186/s13059-017-1347-3

Wang, H., Hu, X., Huang, M., Liu, J., Gu, Y., Ma, L., ... Cao, X. (2019). Mettl3-mediated mRNA m(6)A methylation promotes dendritic cell activation. Nature Communications, 10(1), 1898. https://doi.org/10.1038/s41467-019-09903-6

Wang, R., Luo, Z., He, K., Delaney, M. O., Chen, D., \& Sheng, J. (2016). Base pairing and structural insights into the 5-formylcytosine in RNA duplex. Nucleic Acids Research, 44(10), 4968-4977. https://doi.org/10.1093/nar/gkw235

Wang, X., Lu, Z., Gomez, A., Hon, G. C., Yue, Y., Han, D., ... He, C. (2014). N6-methyladenosine-dependent regulation of messenger RNA stability. Nature, 505(7481), 117-120. https://doi.org/10.1038/nature12730

Wang, R., Zhao, B. S., Roundtree, I. A., Zhike, L., Dali, H., Honghui, M., ... He, C. (2015). N6-methyladenosine Modulates Messenger RNA Translation Efficiency. Cell, 161(6), 1388-1399. https://doi:10.1016/j.cell.2015.05.014

Wang, Y., Zheng, Y., \& Beal, P. A. (2017). Adenosine deaminases that act on RNA (ADARs). Enzyme, 41, 215-268. https://doi.org/10.1016/ bs.enz.2017.03.006

Wei, J., Liu, F., Lu, Z., Fei, Q., Ai, Y., He, P. C., ... He, C. (2018). Differential m(6)A, m(6)Am, and m(1)A demethylation mediated by FTO in the cell nucleus and cytoplasm. Molecular Cell, 71(6), 973-985 e975. https://doi.org/10.1016/j.molcel.2018.08.011

Weinert, B. T., Iesmantavicius, V., Moustafa, T., Scholz, C., Wagner, S. A., Magnes, C., ... Choudhary, C. (2015). Acetylation dynamics and stoichiometry in Saccharomyces cerevisiae. Molecular Systems Biology, 11(10), 833. https://doi.org/10.15252/msb.156513

Wu, C. C., Zinshteyn, B., Wehner, K. A., \& Green, R. (2019). High-resolution ribosome profiling defines discrete ribosome elongation states and translational regulation during cellular stress. Molecular Cell, 73(5), 959-970 e955. https://doi.org/10.1016/j.molcel.2018.12.009

Wu, R., Haas, W., Dephoure, N., Huttlin, E. L., Zhai, B., Sowa, M. E., \& Gygi, S. P. (2011). A large-scale method to measure absolute protein phosphorylation stoichiometries. Nature Methods, 8(8), 677-683. https://doi.org/10.1038/nmeth.1636

Wu, R., Li, A., Sun, B., Sun, J. G., Zhang, J., Zhang, T., ... Yuan, Z. (2019). A novel m(6)A reader Prrc2a controls oligodendroglial specification and myelination. Cell Research, 29(1), 23-41. https://doi.org/10.1038/s41422-018-0113-8

Xiao, W., Adhikari, S., Dahal, U., Chen, Y. S., Hao, Y. J., Sun, B. F., ... Yang, Y. G. (2016). Nuclear m(6)A reader YTHDC1 regulates mRNA splicing. Molecular Cell, 61(4), 507-519. https://doi.org/10.1016/j.molcel.2016.01.012

Xu, L., Liu, X., Sheng, N., Oo, K. S., Liang, J., Chionh, Y. H., ... Fu, X. Y. (2017). Three distinct 3-methylcytidine (m(3)C) methyltransferases modify tRNA and mRNA in mice and humans. The Journal of Biological Chemistry, 292(35), 14695-14703. https://doi.org/10.1074/jbc. M117.798298

Yang, X., Yang, Y., Sun, B. F., Chen, Y. S., Xu, J. W., Lai, W. Y., ... Yang, Y. G. (2017). 5-methylcytosine promotes mRNA export - NSUN2 as the methyltransferase and ALYREF as an m(5)C reader. Cell Research, 27(5), 606-625. https://doi.org/10.1038/cr.2017.55

Yoon, K. J., Ringeling, F. R., Vissers, C., Jacob, F., Pokrass, M., Jimenez-Cyrus, D., ... Song, H. (2017). Temporal control of mammalian cortical neurogenesis by m(6)A methylation. Cell, 171(4), 877-889 e817. https://doi.org/10.1016/j.cell.2017.09.003

You, C., Dai, X., \& Wang, Y. (2017). Position-dependent effects of regioisomeric methylated adenine and guanine ribonucleosides on translation. Nucleic Acids Research, 45(15), 9059-9067. https://doi.org/10.1093/nar/gkx515

Yuan, F., Bi, Y., Siejka-Zielinska, P., Zhou, Y. L., Zhang, X. X., \& Song, C. X. (2019). Bisulfite-free and base-resolution analysis of 5-methylcytidine and 5-hydroxymethylcytidine in RNA with peroxotungstate. Chemical Communications, 55(16), 2328-2331. https://doi. org/10.1039/C9CC00274J

Zaccara, S., Ries, R. J., \& Jaffrey, S. R. (2019). Reading, writing and erasing mRNA methylation. Nature Reviews. Molecular Cell Biology, 20 (10), 608-624. https://doi.org/10.1038/s41580-019-0168-5

Zhang, C., Samanta, D., Lu, H., Bullen, J. W., Zhang, H., Chen, I., ... Semenza, G. L. (2016). Hypoxia induces the breast cancer stem cell phenotype by HIF-dependent and ALKBH5-mediated m(6)A-demethylation of NANOG mRNA. Proceedings of the National Academy of Sciences of the United States of America, 113(14), E2047-E2056. https://doi.org/10.1073/pnas.1602883113

Zhang, L. S., Liu, C., Ma, H., Dai, Q., Sun, H. L., Luo, G., ... He, C. (2019). Transcriptome wide mapping of internal N(7)-methylguanosine methylome in mammalian mRNA. Molecular Cell, 74(6), 1304-1316 e1308. https://doi.org/10.1016/j.molcel.2019.03.036

Zhang, X., Wei, L. H., Wang, Y., Xiao, Y., Liu, J., Zhang, W., ... Jia, G. (2019). Structural insights into FTO's catalytic mechanism for the demethylation of multiple RNA substrates. Proceedings of the National Academy of Sciences of the United States of America, 116(8), 2919-2924. https://doi.org/10.1073/pnas.1820574116

Zhao, X., Yang, Y., Sun, B. F., Shi, Y., Yang, X., Xiao, W., ... Yang, Y. G. (2014). FTO-dependent demethylation of N6-methyladenosine regulates mRNA splicing and is required for adipogenesis. Cell Research, 24(12), 1403-1419. https://doi.org/10.1038/cr.2014.151

Zhao, Y., Karijolich, J., Glaunsinger, B., \& Zhou, Q. (2016). Pseudouridylation of 7SK snRNA promotes 7SK snRNP formation to suppress HIV-1 transcription and escape from latency. EMBO Reports, 17(10), 1441-1451. https://doi.org/10.15252/embr.201642682

Zheng, G., Dahl, J. A., Niu, Y., Fedorcsak, P., Huang, C. M., Li, C. J., ... He, C. (2013). ALKBH5 is a mammalian RNA demethylase that impacts RNA metabolism and mouse fertility. Molecular Cell, 49(1), 18-29. https://doi.org/10.1016/j.molcel.2012.10.015 
Zhong, X., Yu, J., Frazier, K., Weng, X., Li, Y., Cham, C. M., ... Leone, V. (2018). Circadian clock regulation of hepatic lipid metabolism by modulation of m(6)A mRNA methylation. Cell Reports, 25(7), 1816-1828 e1814. https://doi.org/10.1016/j.celrep.2018.10.068

Zhou, H., Kimsey, I. J., Nikolova, E. N., Sathyamoorthy, B., Grazioli, G., McSally, J., ... Al-Hashimi, H. M. (2016). m(1)A and m(1)G disrupt A-RNA structure through the intrinsic instability of Hoogsteen base pairs. Nature Structural \& Molecular Biology, 23(9), 803-810. https:// doi.org/10.1038/nsmb.3270

Zhou, J., Wan, J., Gao, X., Zhang, X., Jaffrey, S. R., \& Qian, S. B. (2015). Dynamic m(6)A mRNA methylation directs translational control of heat shock response. Nature, 526(7547), 591-594.

Zhu, Y., Zhou, G., Yu, X., Xu, Q., Wang, K., Xie, D., ... Wang, L. (2017). LC-MS-MS quantitative analysis reveals the association between FTO and DNA methylation. PLoS One, 12(4), e0175849. https://doi.org/10.1371/journal.pone.0175849

Zielinska, D. F., Gnad, F., Wisniewski, J. R., \& Mann, M. (2010). Precision mapping of an in vivo N-glycoproteome reveals rigid topological and sequence constraints. Cell, 141(5), 897-907. https://doi.org/10.1016/j.cell.2010.04.012

How to cite this article: Jones JD, Monroe J, Koutmou KS. A molecular-level perspective on the frequency, distribution, and consequences of messenger RNA modifications. WIREs RNA. 2020;11:e1586. https://doi.org/10. 1002/wrna.1586 